\title{
Chemical Dynamics, Molecular Energetics, and Kinetics at the Synchrotron
}

\author{
Stephen R. Leone, ${ }^{* \dagger 1}$ Musahid Ahmed, ${ }^{2}$ and Kevin R. Wilson. ${ }^{2}$ \\ ${ }^{1}$ Departments of Chemistry and Physics, University of California \\ ${ }^{2}$ Chemical Sciences Division, Lawrence Berkeley National Laboratory \\ Berkeley, CA 94720 USA \\ E-mail: srl@,berkeley.edu
}

Scientists at the Chemical Dynamics Beamline of the Advanced Light Source in Berkeley are continuously reinventing synchrotron investigations of physical chemistry and chemical physics with vacuum ultraviolet light. One of the unique aspects of a synchrotron for chemical physics research is the widely tunable vacuum ultraviolet light that permits threshold ionization of large molecules with minimal fragmentation. This provides novel opportunities to assess molecular energetics and reaction mechanisms, even beyond simple gas phase molecules. In this perspective, significant new directions utilizing the capabilities at the Chemical Dynamics Beamline are presented, along with an outlook for future synchrotron and free electron laser science in chemical dynamics. Among the established and emerging fields of investigations are cluster and biological molecule spectroscopy and structure, combustion flame chemistry mechanisms, radical kinetics and product isomer dynamics, aerosol heterogeneous chemistry, planetary and interstellar chemistry, and secondary neutral ion-beam desorption imaging of biological matter and materials chemistry.

${ }^{\dagger}$ On appointment as a Miller Research Professor in the Miller Institute for Basic Research in Science. 


\section{Author Summary}

In 2002 Stephen Leone joined the faculty at the University of California, Berkeley, and simultaneously became the Director of the Chemical Dynamics Beamline at the Advanced Light Source; the beamline is a U. S. Department of Energy facility for chemical sciences. Together with Musahid Ahmed and Kevin Wilson, staff scientists at Lawrence Berkeley National Laboratory, the three have built an innovative and effective enterprise for synchrotron work in chemical dynamics, providing novel directions, instruments, and access to innumerable users. Leone is a member of the National Academy of Sciences and a Fellow of the American Academy of Arts and Sciences. He is the recipient of the 2010 Polyani Medal of the Gas Kinetics Division of the Royal Society of Chemistry. Musahid Ahmed has been a member of the chemical dynamics beamline staff since 1995. He did his graduate work with Tony Callear at Cambridge University, and postdoctoral work in Leicester, Manchester and Gottingen. His interests lie in novel applications of VUV radiation to problems in gas phase spectroscopy, biomolecule energetics, imaging mass spectrometry, laser ablation and cluster science. Kevin Wilson joined the chemical dynamics beamline in 2004 and is pioneering heterogeneous chemistry at the beamline. He did

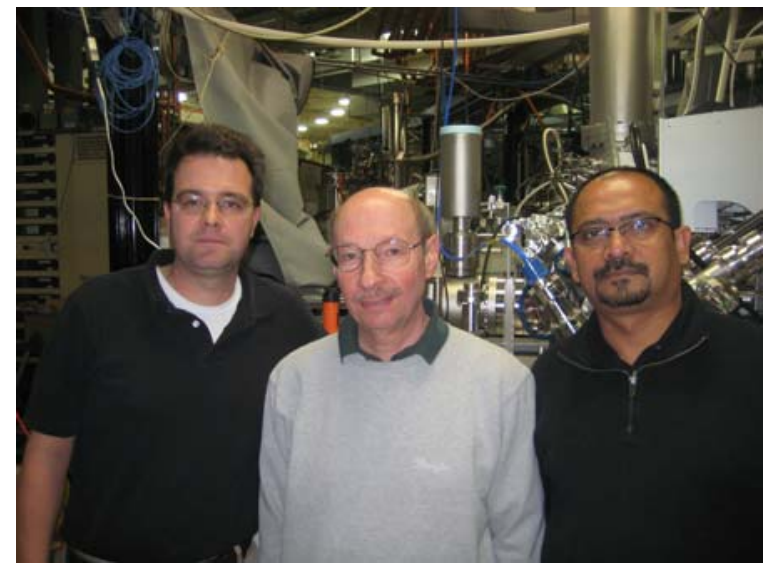

From left: Kevin Wilson, Stephen R. Leone, Musahid Ahmed. his graduate work at UC Berkeley with Richard Saykally. Following this, he received a Fredrick Reines postdoctoral fellowship at Los Alamos National Laboratory. His research interests include novel applications of synchrotron radiation to problems in environmental science. 


\section{Introduction}

The field of chemical dynamics ${ }^{1}$ means many things to many people. In reaction dynamics it can involve basic kinetics or energetics, ${ }^{2}$ or it can represent the most elegant experiments in state-resolved ${ }^{3}$ and angular details, ${ }^{4}$ even coherence effects. ${ }^{5}$ It can be science performed with the shortest pulses in the world, in the attosecond time domain. ${ }^{6}$ More broadly, chemical dynamics involves complex processes, such as combustion and heterogeneous chemistry, ${ }^{7}$ with concurrent impacts on atmospheric chemistry, radiative forcing, and global warming. ${ }^{8}$ Even at the single molecule level, scientists learn about biological events, often with new pairs of eyes, ${ }^{9-11}$ or with their hands on the force tweezers, ${ }^{12}$ these techniques are developed over the years by physical chemists, chemical physicists, and physicists. Such scientists have pioneered many of the instruments and methods that provide the exquisite capabilities today to probe molecular dynamics.

At synchrotrons ${ }^{13}$ throughout the world, technological advances are often the driving force for new experimental platforms, which are shared by many users once they are developed. It takes time to develop these instruments, called end stations at synchrotrons, especially when the state-of-the-art is embraced. At national laboratories, investments in future developments and national facilities are an important role that agencies, such as the U. S. Department of Energy, play. While synchrotrons are clearly a part of big science (Figure 1 shows a picture of the Advanced Light Source and Figure 2 is part of the undulator and front end leading to the Chemical Dynamics Beamline), for all practical purposes, for individual investigators on the synchrotron floor, the instrument platforms are small science (Figure 3), yet often benefitting from the outstanding long-term institutional memory, permanent support, and cutting edge improvements. In the best of all worlds, the support personnel, i.e the beamline scientists, pursue 
their own inspiring research programs, adding further to the capabilities and knowledge base for users at the facility.

In this perspective article, the science revolving around a beamline managed by the authors, the Chemical Dynamics Beamline of the Advanced Light Source in Berkeley (Figure 4), is considered in the broad context of spectroscopy, kinetics, and chemical dynamics, both gas phase and heterogeneous chemistry. The Chemical Dynamics Beamline, established by Nobel Laureate Yuan T. Lee, is the oldest source of tunable vacuum ultraviolet (VUV) light at a third generation synchrotron; it is an undulator beamline that produces nominally radiation from 7.4$25.4 \mathrm{eV} .{ }^{14-16}$ The VUV beamline output flux and bandwidth characteristics have in many ways remained unchanged over the years, since they are properties of the undulator, optical elements, and the electron energy in the storage ring. However, by continuously reinventing and

developing original new platforms that are wheeled onto the floor of the beamline, ${ }^{17-19}$ and with some upgrades to the synchrotron itself (e.g. top off mode of operation ${ }^{20}$ ), highly innovative physical chemistry and chemical physics experiments continue to be done almost fifteen years after its inception.

\section{A Synchrotron Beamline for Chemical Dynamics ${ }^{21}$}

The original configuration ${ }^{22}$ of the vacuum ultraviolet beamline at the Advanced Light Source incorporated a high resolution monochromator $(0.001-0.01 \%$ bandwidth $\Delta \mathrm{E} / \mathrm{E})$ for spectrally resolved ionization studies of gaseous molecules and a crossed beam machine for dynamics investigations. The concepts for how to use synchrotron radiation for chemical dynamics investigations, embodied in these two platforms, have not changed significantly over the years. In one case, high spectral resolution provides narrow band tunable synchrotron radiation to measure spectroscopic features of molecular ionization, the results of which also 
provide important energetic and thermodynamic information; ${ }^{23-25}$ these spectral measurements thus reveal structural information about novel molecules, clusters, and isomers (molecules with the same chemical formula but different structural configurations). Coincidence methods are sometimes incorporated to enhance the power of such spectroscopic investigations, ${ }^{26}$ and threshold ionization coincidence techniques also provide state-selected preparation of ions for novel state-resolved reaction dynamics studies. ${ }^{27}$ The monochromator can also be replaced with a Fourier transform interferometer, which is a new feature at Synchrotron Soleil. ${ }^{28}$

The second broad use of the synchrotron radiation is a means of detecting molecules by tunable wavelength vacuum ultraviolet photoionization. Using tunable VUV radiation, fragments produced by photodissociation and products of crossed beam reactions were detected by the nearly fragmentation-free ionization of nascent species. ${ }^{29,30}$ Tunable wavelengths can resolve all-important isomer details as well. ${ }^{31}$ In this use of the VUV light, the tunable, high flux broadband radiation from the undulator itself $\left(10^{16}\right.$ photons per second, $2.5 \%$ bandwidth), or from a monochromator with more modest spectral resolution $\left(10^{14}\right.$ photons per second, $0.1 \%$ bandwidth) ionizes molecules, and the electrons or ions are detected. At the Chemical Dynamics Beamline, a relatively simple 3 meter monochromator with moderate spectral resolution has been very versatile and more utilitarian than the original very high resolution monochromator. Such an arrangement produces more flux for sensitive product detection, it is easier to align and tune, and it still provides enough resolution to separate most isomer species.

Since the development of the tunable VUV undulator beamline at the Advanced Light Source, the basics of this design have been incorporated into other synchrotrons throughout the world (both undulator and bend magnet beamlines). There are over 60 synchrotron sources in the world today. Many are pursuing or proposing molecular dynamics and chemical physics 
investigations with VUV radiation, including, but not limited to, the National Synchrotron Radiation Research Center in Taiwan, the Hefei National Synchrotron Radiation Laboratory and the newly commissioned Shanghai Synchrotron Radiation Facility, the Swiss Light Source, the Brazilian Synchrotron Light Laboratory, Bessy II in Berlin, MAX-lab in Lund, Elettra in Trieste, UVSOR in Japan, Synchrotron Soleil in France, INDUS in India, and SESAME in Jordan. Newer synchrotrons and beamlines have introduced innovative source capabilities such as elliptically polarized undulators, which can be used for circular dichroism in the VUV; ${ }^{32}$ some have improved on devices to eliminate high harmonics from the undulator ${ }^{33}$ (based on the same

principle of gas absorption used at the ALS); ${ }^{16}$ high resolution is achieved with Fourier transform interferometers; ${ }^{28}$ some have built impressive end stations with superb count rates and detection capabilities. The Chemical Dynamics Beamline at the Advanced Light Source has advanced by innovations in end station platforms, pioneering new science capabilities to study flames, kinetics, aerosols, and imaging, and by merging end stations with lasers for two color experiments.

\section{Structure/Spectroscopy}

Tunable VUV radiation when coupled to molecular beam mass spectrometry allows access to information such as ionization onsets and, depending on resolution, to the nature of excitation in the cationic species. This, in turn, coupled with thermodynamic analysis leads to neutral bond dissociation energies, the results of which are important in a number of fields ranging from combustion to interstellar chemistry. At the Chemical Dynamics Beamline, a new apparatus has been developed ${ }^{34,35}$ (Figure 5) to generate clusters (C, Si, Au, Pt, and Fe are some of the systems under study at the beamline) via laser ablation. Typically a rare gas is used to coexpand the beam of laser-ablated species, and substituting the expansion rare gas with other 
reactive gases such as oxidizers $\left(\mathrm{N}_{2} \mathrm{O}, \mathrm{CO}_{2}, \mathrm{O}_{3}\right)$ or hydrocarbons $\left(\mathrm{C}_{2} \mathrm{H}_{2}, \mathrm{C}_{2} \mathrm{H}_{4}, \mathrm{CH}_{4}, \mathrm{C}_{4} \mathrm{H}_{2}, \mathrm{C}_{4} \mathrm{H}_{4}\right.$, $\mathrm{C}_{6} \mathrm{H}_{6}$ ) leads to the generation of novel species formed in reaction between the laser ablated species and the carrier gas. This technique has allowed the first direct detection of gas phase $\mathrm{SiO}_{2}$ formed via reaction of $\mathrm{Si}$ with $\mathrm{CO}_{2}{ }^{36}$ A state-to-state ionization energy for $\mathrm{SiO}_{2}$ of 12.60 $( \pm 0.05) \mathrm{eV}$ is obtained by fitting two prominent peaks in the PIE curve to the following transitions from the electronically ground state of the neutral to the electronically ground state of the cation: ${ }^{1} \Sigma \mathrm{O}-\mathrm{Si}-\mathrm{O} \rightarrow{ }^{2} \Sigma_{\mathrm{g}}[\mathrm{O}-\mathrm{Si}-\mathrm{O}]^{+}$. (Figure 6) Electronic structure calculations aid in the interpretation of the photoionization process and allow for identification of the symmetric stretch in ${ }^{2} \Sigma_{\mathrm{g}}[\mathrm{O}-\mathrm{Si}-\mathrm{O}]^{+}$, which is observed in the PIE spectrum to be $0.11 \mathrm{eV}\left(890 \mathrm{~cm}^{-1}\right)$ above the ground state of the cation. The result agrees with the $892 \mathrm{~cm}^{-1}$ symmetric stretch frequency of ${ }^{2} \Sigma_{\mathrm{g}}[\mathrm{O}-\mathrm{Si}-\mathrm{O}]^{+}$calculated at the CCSD(T)/aug-cc-pVTZ level. ${ }^{36}$

Other notable results are the measurement of the ionization energies of small carbon ${ }^{37}$ and silicon ${ }^{38}$ clusters, ionization energies of isomers of hydrocarbon free radicals $\left(\mathrm{C}_{3} \mathrm{H}^{39}{ }^{39} \mathrm{C}_{4} \mathrm{H}_{3}{ }^{40}\right)$ and precise determinations of the ionization energies of $\mathrm{FeO},{ }^{34} \mathrm{PtC}, \mathrm{PtO}$ and $\mathrm{PtO}_{2} \cdot{ }^{41}$ Recent work has focused on the reactivity of gold and the gold dimers with hydrocarbons and $\mathrm{CO}$ and reactions of carbon clusters with $\mathrm{N}_{2} \mathrm{O}$ to generate long chain $\mathrm{C}_{\mathrm{n}} \mathrm{N}^{42}$ and $\mathrm{C}_{\mathrm{n}} \mathrm{O}$ clusters. In some cases previous literature values for ionization energies are in error by more than $0.5 \mathrm{eV}$. In all of these studies, theory plays a complementary role in elucidating the nature of the ionization process, and, in some cases, theory allows for the identification of electronically excited states, in the carbon trimer cation, ${ }^{35}$ and the vibrational symmetric stretch in the ${ }^{2} \Sigma_{\mathrm{g}}[\mathrm{O}-\mathrm{Si}-\mathrm{O}]^{+}$state in the case of $\mathrm{SiO}_{2}$ cation mentioned earlier. ${ }^{36}$

Fundamental studies of photoionization processes of biomolecules are necessary for their implementation in imaging mass spectrometry. Furthermore determinations of ionization 
energies and other properties of biomolecules in the gas phase are not trivial and these results provide important benchmarks for theoretical methods and generate key information for biomolecule energetics. A thermal vaporization technique coupled with supersonic molecular beams, which provides a gentle way to generate these species in the gas phase, was developed at the beamline. ${ }^{43}$ This source allows for detailed investigations of the micro-solvation of individual DNA bases with small water clusters. ${ }^{43}$ Gas phase clusters of water with DNA bases (Guanine (G), Cytosine (C), Adenine (A) and Thymine (T)) are generated via thermal vaporization and expansion of the resultant vapor into a continuous supersonic jet expansion of the bases seeded with water. Photoionization efficiency curves (PIE) are recorded for the isolated DNA bases and several water (W) clusters with the bases $-\mathrm{G}, \mathrm{GW}_{\mathrm{n}}(\mathrm{n}=1-3) ; \mathrm{C}, \mathrm{CW}_{\mathrm{n}}(\mathrm{n}=1-3)$; $A$, $\mathrm{AW}_{\mathrm{n}}(\mathrm{n}=1,2) ; \mathrm{T}, \mathrm{TW}_{\mathrm{n}}(\mathrm{n}=1-3)$. Appearance energies (AE) are derived from the onset of these PIE curves. The AE's of the DNA bases decrease slightly with the addition of water molecules (up to 3) but do not converge to values found for photo-induced electron removal from DNA bases in solution.

Judicious combinations of source gas and temperature form dimers and higher clusters of the DNA bases using the same source. At the Chemical Dynamics Beamline some of the first experimental measurements of the ionization energies of DNA base dimers (AA, TT, AT, CC, GG, and GC) have been performed. Comparison of the experimental results with theoretical calculations from the Krylov group (University of Southern California) reveals the effects of noncovalent interactions, i.e., hydrogen bonding, stacking, and electrostatic interactions, on the IEs of the individual nucleobases. ${ }^{44,45}$ For TT, the largest changes in vertical IEs $(0.4 \mathrm{eV})$ relative to the monomer occur in asymmetric hydrogen-bonded and symmetric-stacked isomers, whereas in the lowest-energy symmetric hydrogen-bonded dimer the shift in IEs is much smaller 
$(0.1 \mathrm{eV})$. The origin of the shift and the character of the ionized states are different in asymmetric hydrogen-bonded and symmetric stacked isomers. In the former, the initial hole is localized on one of the monomers, and the shift is due to the electrostatic stabilization of the positive charge of the ionized monomer by the dipole moment of the neutral monomer. In the latter, the hole is delocalized, and the change in IE is proportional to the overlap of the monomers' molecular orbitals (MOs). The shifts in AA and AT are much smaller due to a less efficient overlap, the smaller dipole of A, and the large energy gap between ionized states of A and $\mathrm{T}$ monomers in the case of the AT dimer. The ionization of the hydrogen-bonded dimers results in a nearly barrierless proton transfer, whereas the $\pi$-stacked dimers relax to structures with the hole stabilized by the delocalization or electrostatic interactions. For cytosine it is revealed that the large red shift $(0.7 \mathrm{eV})$ of the first IE of the lowest-energy cytosine dimer is due to strong inter-monomer electrostatic interactions, i.e., the hole localized on one of the monomers is stabilized by the dipole moment of the other. Both experimental and theoretical results suggest that a number of tautomers and hydrogen-bonded dimers are present in the molecular beam, however, more quantitative analysis will require calculations of Frank Condon Factors and ionization cross-sections.

In recent work an experimental apparatus was adapted to perform mass analyzed threshold ionization (MATI) at the synchrotron. ${ }^{46}$ This opens up a novel way to perform photoionization spectroscopy at the beamline that can improve spectral resolution in ionization onset measurements as well as generate structural information on the cation. The idea is to have access to spectroscopy that is typically only available using photoelectron spectroscopy but with mass resolution. MATI spectroscopy was performed using reflectron time-of-flight mass spectrometry coupled to a simple but unique pulsed field ionization scheme for the effective 
separation of the MATI signal from the prompt ion signal. ${ }^{46}$ It has been demonstrated for the first time that synchrotron-MATI can be applied even to polyatomic molecules for which high-n Rydberg states are subject to a number of decay channels. For Ar, a number of resolved bands below the ionization energy are observed, which are ascribed to high-n,l Rydberg states prepared in the MATI scheme. The first vibrational state resolved MATI spectra of $\mathrm{N}_{2}$ and $\mathrm{O}_{2}$ were observed and the spectral characteristics considered in comparison to previously-reported threshold photoelectron spectroscopic studies. Figure 7 shows MATI spectra for $\mathrm{N}_{2} \mathrm{O}, \mathrm{H}_{2} \mathrm{O}$, $\mathrm{C}_{2} \mathrm{H}_{2}$, and $\mathrm{C}_{6} \mathrm{H}_{6}$, some of the polyatomic molecules studied at the beamline. The successful synchrotron-MATI spectra of polyatomic molecules demonstrate that MATI spectroscopy can be conventionally implemented at a synchrotron facility to provide a universal ionization spectroscopy technique and can be applied to a wide variety of chemical systems including biological molecules, hydrogen-bonded species, carbon and metal clusters, and radicals formed in combustion processes.

\section{Flame Combustion Mechanisms}

A flame sampling molecular beam mass spectrometer was constructed as part of an international colloboration involving many researchers from Sandia National Laboratory, Cornell University, Bielefeld University, Lawrence Berkeley National Laboratory, and the University of Massachusetts, Amherst. ${ }^{47,48}$ While the overall design of the instrument ${ }^{49}$ follows well established techniques, a key innovation of this instrument is the use of tunable VUV photoionization mass spectrometry for flame analysis. This approach allows researchers to examine the isomeric composition of stable molecules and radical species generated in a flame essentially in situ. The detection and quantification of combustion species with isomeric identification provides ever more stringent tests of combustion models and mechanisms; in 
particular those reaction pathways that lead to unwanted gas (e.g. $\mathrm{NO}_{\mathrm{x}}$ ) and particle phase (soot) combustion byproducts (i.e. pollutants) may be explored. These kinds of measurements are expected to play a key role in elucidating changes in combustion chemistry that might occur with the introduction of advanced engine designs ${ }^{50}$ and novel bio-derived fuels and to bio-fuels. ${ }^{51}$

The flame machine, shown in Figure 8, houses a low pressure laminar flame produced by a McKenna burner. Chemical species are extracted out of the flame using a quartz probe to form a molecular beam, which is skimmed once and then directed into a time-of-flight mass spectrometer, where radicals and stable molecules are photoionized by tunable VUV radiation. The distance between the quartz probe and the burner surface can be adjusted to ultimately obtain mole fraction profiles for individual species as a function of position in the flame. Isomer identification is obtained by scanning the photon energy to obtain photoionization efficiency spectra. The ability to measure isomers has led to exciting discoveries, such as the observation of an entirely new class of molecules in flames, enols, which were completely absent in kinetic models of combustion. ${ }^{52}$ Shown in Figure 9 are PIE scans of $m / z=44$ for four different flames. It is clear that ethenol $\left(\mathrm{CH}_{2}=\mathrm{CHOH}\right)$ is well separated from acetaldehyde $\left(\mathrm{CH}_{3} \mathrm{CHO}\right)$. In general, these kinds of isomerically resolved data provide critical tests of computer models of combustion.

The flame apparatus has been used to characterize over forty different flames for over ten different fuels. ${ }^{31}$ One of the principal themes of the current research is developing an understanding of molecular weight growth mechanisms that are ultimately responsible for the formation of polycyclic aromatic hydrocarbons, which are precursors to soot. One approach is to examine flames of different isomeric fuels in an effort to understand how differences in fuel structure alter molecular weight growth chemistries. For example, it was found that a 1-hexene 
flame yields a larger number of $\mathrm{C}_{2}-\mathrm{C}_{5}$ molecules compared to its cyclic isomer, cyclohexane. The formation of these smaller $\mathrm{C}_{2}-\mathrm{C}_{5}$ species are important reactive precursors for benzene formation, which could explain the differences in the fulvene/benzene ratios observed in these isomeric fuels. ${ }^{31}$ In another example, it was observed that an allene $\left(\mathrm{C}_{3} \mathrm{H}_{4}\right)$ flame produces larger quantities of the $\mathrm{C}_{6} \mathrm{H}_{6}$ isomer fulvene than a flame generated from another $\mathrm{C}_{3} \mathrm{H}_{4}$ isomer;

propyne. ${ }^{47}$ This approach of combining isomeric fuels with isomer resolved VUV detection of combustion products is proving to be powerful method for elucidating complex and, in some cases, subtle features of soot formation pathways as recently discussed. ${ }^{31}$

Another principal research theme is to undertake an extensive study of the chemistry of oxygenated and nitrogenated biofuels, which have been proposed as clean burning, renewable alternatives to conventional petroleum based hydrocarbons. These studies are essential for developing kinetic models to predict how novel bio-derived fuel stocks might impact the performace and emission characteristics of existing and state-of-the-art engine designs. Furthermore, the higher nitrogen and oxygen content in biofuels makes elucidating the formation pathways of $\mathrm{NO}_{\mathrm{x}}$ and soot a significant outstanding challenge. For example, one recent study focused on understanding how molecular structure influences fuel decomposition pathways for small esters, a key structural element of many modern biofuels. ${ }^{53}$

\section{Isomer Products of Reactive Chemistry}

In a collaboration with David Osborn and Craig Taatjes of the Combustion Research Facility at Sandia National Laboratories, a new end station was developed to study product species and, in particular, isomers of elementary gas phase reactions. ${ }^{17}$ The apparatus (Figure 3) comprises a temperature variable reaction flow cell, laser photodissociation to produce radical species, a side-sampling orifice to extract a small fraction of the products into the synchrotron 
beam, tunable vacuum ultraviolet ionization of the sampled reaction gases, and mass spectrometric analysis. By using tunable vacuum UV photoionization, the ubiquitous fragmentation of parent molecule species that occurs with electron impact ionization is minimized, and the chemical identities of isomers are often resolved.

The power of the method is illustrated in Figure $10,{ }^{17}$ using as an example a chemical system to study the formation of $\mathrm{C}_{6} \mathrm{H}_{6}$ by the recombination of two $\mathrm{C}_{3} \mathrm{H}_{3}$ molecules, such as would occur in combustion as a precursor to sooting. Photolysis of propargyl chloride results in a clear signature of propargyl radical, $\mathrm{C}_{3} \mathrm{H}_{3}$, which is the precursor to the reaction, and the product isomers show significant fractions of fulvene and 1,5-hexadiyne, among other isomers of $\mathrm{C}_{6} \mathrm{H}_{6}$.

Using this apparatus, a wide range of other reactive systems related to problems in combustion have been studied (e.g. enol formation, ring opening reactions, gas phase Criegee intermediates) as well as many reactions important for the interstellar medium and planetary atmospheres. ${ }^{54-57}$ Examples of the latter, which also have applications to combustion, isomers of $\mathrm{C}_{5} \mathrm{H}_{4}$ were quantified in the reactions of $\mathrm{C}_{2} \mathrm{H}$ with $\mathrm{C}_{3} \mathrm{H}_{4}$ (propyne and allene). ${ }^{58}$ With allene the products are $35-45 \%$ ethynylallene, $20-25 \%$ methyldiacetylene, and 45-30\% 1,4-pentadiyne. The other possible product, diacetylene $\left(\mathrm{C}_{4} \mathrm{H}_{2}\right)$, is not observed for this reaction $(<30 \%)$, whereas for $\mathrm{C}_{2} \mathrm{H}$ with propyne $\left(\mathrm{CH}_{3} \mathrm{CCH}\right)$ the diacetylene product has an abundance of $50-70 \%$. A comprehensive investigation of the reactions of the methylidyne radical $(\mathrm{CH})$ with ethylene, acetylene, allene, and methylacetylene (propyne) was performed using the tunable synchrotron analysis. ${ }^{59}$ The reactions proceed by either $\mathrm{CH}$ insertion or addition followed by $\mathrm{H}$ atom elimination from the intermediate adduct. For the $\mathrm{CH}+\mathrm{C}_{2} \mathrm{H}_{4}$ reaction, the $\mathrm{C}_{3} \mathrm{H}_{5}$ intermediate decays by $\mathrm{H}$ atom loss to form $70 \pm 8 \%$ allene, $30 \pm 8 \%$ methylacetylene (propyne), and $<10 \%$ 
cyclopropene. In the $\mathrm{CH}+\mathrm{C}_{2} \mathrm{H}_{2}$ reaction, the cyclic $\mathrm{C}_{3} \mathrm{H}_{2}$ product is primarily observed, in contradiction to previous calculations, which suggested that linear triplet propargylene $(\mathrm{HCCCH})$ accounts for $90 \%$ of the product formation. New calculations ${ }^{59}$ indicate that a somewhat higher production of the cyclic product (27\%) should be expected, however, from these calculations together with $\mathrm{D}$ atom isotope studies, it was shown that subsequent $\mathrm{H}$-atom assisted isomerization of the triplet propargylene is most likely responsible for the additional large conversion to the observed $\mathrm{c}-\mathrm{C}_{3} \mathrm{H}_{2}$. Cyclic isomers are also observed for the reaction of $\mathrm{CH}$ with methylacetylene. In contrast, the reaction of $\mathrm{CH}$ with allene produces $23 \pm 5 \% 1,2,3$-butatriene, and $77 \pm 5 \%$ vinylacetylene, and no cyclic isomers are detectable. Such studies greatly revise the understanding of the $\mathrm{C}_{2} \mathrm{H}$ and $\mathrm{CH}$ reaction systems and the formation of cyclic isomers, demonstrating the power of isomer specific detection experiments.

\section{Aerosol Heterogeneous Chemistry}

In 2004, a new endstation, dedicated to the VUV analysis of submicron particles, ${ }^{18}$ was commissioned by beamline personnel. This endstation consists of an aerodynamic lens that samples nanometer-sized aerosols from atmospheric pressure to form a tightly focused $(\sim 1 \mathrm{~mm}$ diameter) beam of particles that can be interrogated with synchrotron radiation. This endstation is one element in an extensive experimental platform, which consists of differential mobility analyzers, condensation particle counters, reactors, atomizers and particle nucleators, to provide users and beamline staff tremendous flexibility in generating a wide variety of aerosol particles, for studying heterogeneous chemistry, and in characterizing aerosol size and composition. Initial studies focused on developing experimental methods to measure size-resolved optical properties, via VUV Mie scattering, ${ }^{60,61}$ and to obtain the angular distribution of photoelectrons using velocity map imaging spectroscopy. ${ }^{62}$ These measurements demonstrated that VUV radiation 
affords new possibilities of probing the electronic structure of biomolecule aerosols ${ }^{63}$ as well as size-selected free nanoparticles ${ }^{62}$ in ways that are not easily done using optical wavelengths.

Recently, the aerosol endstation is being used for compositional analysis of organic aerosol particles, taking advantage of VUV photoionization mass spectrometry. In this endstation configuration, the aerosol beam is directed into an oven and the organic aerosol is vaporized. The resulting gas plume is then photoionized to obtain a chemical picture of the aerosol using time-of-flight mass spectrometry. In most cases, threshold photoionization, using VUV radiation, preserves the parent molecular ion peak in the mass spectrum, since the molecule of interest is ionized with minimal amounts of internal energy. Thus dissociative photonionization is reduced, producing a mass spectrum that is uncongested by small ion fragments. Measuring heterogeneous reaction probabilities of very large molecules in aerosols, via mass spectrometry, requires identifying a unique feature in the mass spectrum that can be used to monitor the reactant as a function of reaction conditions. In $70 \mathrm{eV}$ electron impact ionization, different, large organic molecules are fragmented into similar sets of small ion fragments, which make distinguishing the reactant from product molecules nearly impossible. This is usually not the case in VUV photoionization. For example, the electron ionization spectrum (Figure 11) of an aerosol of squalane $\left(\mathrm{C}_{30} \mathrm{H}_{62}\right)$ consists of many small fragment ions with $\mathrm{m} / \mathrm{z}<100$, while the VUV spectrum consists mainly of the parent molecular ion peak at $\mathrm{m} / \mathrm{z}$ $=422$, which can be clearly distinguished from other species that are formed during a heterogeneous reaction.

It was shown ${ }^{64,65}$ that the overall fragmentation pattern in a VUV mass spectrum of an aerosol is a sensitive function of the internal energy of the neutral, which is controlled by the aerosol vaporization temperature, and the energy in the cation, which is determined by the 
energy of the ionizing photon. Such fundamental studies of how internal energy controls dissociative photoionization in larger molecules (e.g. $\mathrm{C}_{30} \mathrm{H}_{62}$ ) are only possible using a tunable VUV source. In practical terms, the proper selection of the oven temperature and photon energy yields parent molecular ion peaks, which are readily assigned to individual molecular species within an aerosol particle. It is this enhancement of molecular information in the VUV photoionization aerosol mass spectrum that is currently used by a number of research groups for the real time chemical analysis of complex multi-component organic particles, such as diesel soot, tobacco smoke, and secondary organic aerosol.

Currently, a significant number of studies are undertaken to use the VUV aerosol mass spectrometer to measure the fundamental heterogeneous reactivity of organic particles with species such as $\mathrm{O}_{3}{ }^{65}, \mathrm{OH} \cdot{ }^{66,67}$ and $\mathrm{Cl}$. These efforts are aimed at building a molecular level understanding of reactions occurring at interfaces that govern a wide array of environmentally and technologically important processes ranging from soot formation and oxidation, aerosol aging, electron transport across membranes, lipid peroxidation, corrosion, hydrocarbon cracking, and heterogeneous catalysis. In these studies, VUV photoionization aerosol mass spectrometry is used to measure heterogeneous reaction probabilities and product distributions, needed to formulate detailed reaction mechanisms.

As shown in Figure 12, VUV photoionization can be used to measure the kinetic evolution of squalane and its reaction products, all of which are formed during the heterogeneous reaction with hydroxyl radicals in the presence of $\mathrm{O}_{2}$. The decay of squalane is accompanied by the kinetic evolution of oxygenated products, which are uniquely identified in the VUV photoionization mass spectra. Such kinetic data has been used to compute both the $\mathrm{OH}+$ squalane heterogeneous reaction probability as well as to formulate a detailed sequential reaction 
mechanism in which it is found that one oxygenated functional group is added per squalane/OH

reaction. ${ }^{66,67}$ In general, these kinds of measurements provide critical data to evaluate how gas or condensed phase reaction mechanisms are modified at organic surfaces.

Other studies, similar to those outlined above, are currently underway to examine key heterogeneous reactions that are expected to play important roles in understanding the atmospheric chemistry of diesel emissions as well as heterogeneous processes that might be important in the formation of soot or in the combustion of biofuel sprays, as well as the degradation of particulate pollution in the environment.

\section{Planetary and Interstellar Chemistry}

While many experiments at the beamline use the tunable VUV light for ionization, a number of experiments, mostly using flow cells, use the light for direct absorption and photodissociation at VUV wavelengths. These are particularly important for studying dissociation processes occurring in planetary and interstellar chemistry. Two groups, Mark Thiemens (University of California, San Diego (UCSD)) and Mark Smith (University of Arizona) developed experiments at the beamline to probe the early solar system photochemistry of $\mathrm{CO}$ and molecular growth processes upon photodissociation and ionization in Titan's atmosphere, respectively. The $\mathrm{CO}$ experiment resolved a long standing controversy regarding the origin of isotopic anomalies in the oxygen isotope content of meteorites that fall to earth. It was suggested the isotopic abundances arise from a process termed "self shielding" in which VUV light from the proto sun would dissociate CO's isotopologues differently, and depending on column density (Beer-Lambert Law), ${ }^{17} \mathrm{O}$ and ${ }^{18} \mathrm{O}$ would be enriched due to saturation of absorption of light for the ${ }^{16} \mathrm{O}$. The resulting ${ }^{17} \mathrm{O},{ }^{18} \mathrm{O}$ rich oxygen atoms would react with hydrogen to form water and subsequently exchange on silicates resulting in the enrichment 
observed in the meteorites arriving on earth. Experiments at the beamline showed that the selfshielding hypothesis is not valid and that the anomalous distributions observed in VUV photodissociation of $\mathrm{CO}$ can be explained by accidental pre-dissociation of excited states of $\mathrm{CO}^{68,69}$ The analysis of the CO photodissociation experiment was performed at UCSD where the oxygen content is determined by high resolution isotope mass spectrometry. This is a very good illustration of how basic chemical physics can play an important role in unraveling complicated phenomenon that occur in nature. These results have important ramifications in the analysis of solar wind samples collected by NASA's GENESIS mission in determining the composition of the solar nebula. Future work will tackle unresolved issues in sulfur cosmochemistry.

Mark Smith and co-workers performed analysis of products formed in the photodissociation of nitrogen/methane mixtures (to simulate Titan's atmosphere). ${ }^{70,71}$ In online experiments, the neutral products are analyzed by an electron impact mass spectrometer, (Figure 13 (a)) while species ionized by the VUV radiation are detected with a second mass spectrometer. High molecular weight products are also analyzed off site using very high resolution mass spectrometry. At wavelengths $<80 \mathrm{~nm}$, the presence of the dominant $\mathrm{N}_{2}$ species in a $\mathrm{N}_{2} / \mathrm{CH}_{4}$ gas mixture selectively enhances the formation of unsaturated hydrocarbons (Figure 13 (b), such as benzene and toluene, while photochemistry in pure methane leads to a mixture of saturated/unsaturated hydrocarbon species (Figure $13(\mathrm{c})$ ). The authors postulate that this enhanced formation of unsaturated hydrocarbons is most likely initiated by the generation of $\mathrm{CH}_{3}{ }^{+}$via a dissociative charge-transfer reaction between $\mathrm{N}_{2}{ }^{+}$and $\mathrm{CH}_{4}$. In contrast, the depleted fraction of unsaturated species from a $\mathrm{H}_{2} / \mathrm{CH}_{4}$ gas mixture suggests that the $\mathrm{CH}_{5}{ }^{+}$ion generated via a proton-transfer reaction is not an important precursor in the production of complex 
unsaturated hydrocarbons. These results directly support the understanding of the photochemistry in the upper atmospheres of Titan and the Jovian planets.

The isomer-specific product detection apparatus used for the gas phase kinetic studies, when combined with a low temperature Laval nozzle kinetics apparatus, ${ }^{72}$ provides a powerful means to analyze reactive events important to the chemistry in the interstellar medium and planetary atmospheres. An example of an investigation of product species that relates to the planetary atmosphere of Titan may be given; performed at room temperature, it involves $\mathrm{CN}$ radical reactions with ethene and propene. ${ }^{73}$ Both reactions proceed by the addition of $\mathrm{CN}$ to the double bond. For $\mathrm{CN}+$ ethylene, the sole product is cyanoethene, $\mathrm{C}_{2} \mathrm{H}_{3} \mathrm{CN}$. For $\mathrm{CN}+$ propene, multiple products are identified, with $75 \pm 15 \%$ being cyanoethene via $\mathrm{CH}_{3}$ elimination and $25 \pm 15 \%$ being several isomers of $\mathrm{C}_{4} \mathrm{H}_{5} \mathrm{~N}$ via $\mathrm{H}$ elimination. There is no evidence for $\mathrm{HCN}$ formation by direct abstraction of an $\mathrm{H}$ atom. The formation of unsaturated nitriles on Titan is implicated in haze formation in the planetary atmosphere, via polymerization through reactions of $\mathrm{CN}$ with cyanoethene to create polymer species. ${ }^{74}$

Using low temperature Laval nozzle techniques to study reaction rate constants by kinetic rates, numerous other reactions have been explored down to the $\approx 100 \mathrm{~K}$ temperatures relevant to Titan, including $\mathrm{CN}$ with benzene and toluene. ${ }^{75}$ Recognizing that mechanisms of elementary reactions are altered from low to high temperatures, a new end station platform is under construction to couple the Laval technique with tunable vacuum ultraviolet product detection at the Chemical Dynamics Beamline, thus allowing user groups to obtain quantitative product information and kinetic rate constant data on reactions down to approximately $100 \mathrm{~K}$. With the high temperature capability of the original product detection apparatus, ${ }^{17}$ reactions may be 
studied definitively over a wide range of temperatures where mechanisms will most likely change from addition-elimination to direct abstraction.

\section{Imaging Mass Spectrometry}

There is enormous interest in understanding how nanoscale features on surfaces - both inorganic and biological - influence their chemistry. ${ }^{76,77}$ Development of new microscopic techniques to detect and identify molecules with high spatial resolution can significantly advance the study of more complex nano-scale chemistry. At the Chemical Dynamics Beamline, a technique is being developed to perform chemical imaging on surfaces using a novel mass spectrometry method, wherein ion-sputtered neutrals are photoionized with high fluxes of tunable-wavelength synchrotron VUV light, i.e. VUV-SNMS (Secondary Neutral Mass Spectrometry). Traditional electron and optical based imaging techniques generally lack sufficient chemical specificity at the molecular level for the understanding of complex chemical systems prevalent in nature. Mass spectrometric imaging using ion nanoprobes offers a solution to this long-standing problem, allowing the localization of specific chemical species on length scales of $100 \mathrm{~nm}$ or less. ${ }^{78}$

Conventional imaging mass spectrometry involves the detection of secondary ions (secondary ion mass spectrometry or SIMS) or laser postionized neutral species (SNMS), the latter often involving harsh multiphoton ionization conditions. The resulting mass spectra from these techniques are complicated by excessive fragmentation and are difficult to analyze. By utilizing VUV photons to threshold ionize the ion-sputtered neutral species, a minimal amount of energy is deposited in the desorbed molecule and thereby significantly simplified mass spectra are acquired whose intensities are representative of the surface composition. 
Initial exploratory experiments were performed on metal systems to optimize the apparatus for VUV post-ionization. ${ }^{79}$ These results allow for the comparison of signal strengths of VUV-SNMS with traditional SIMS , as well as the analysis of internal energy deposited into the neutral molecules by the desorption process. Neutral post-ionization signals are observed from various inorganic substrates, including $\mathrm{Ag}, \mathrm{Cu}, \mathrm{Si}, \mathrm{In}, \mathrm{Ge}, \mathrm{Pt}, \mathrm{Zn}, \mathrm{Au}$ and GaAs. Extended studies were performed for GaAs and $\mathrm{Au}^{79}$ Mass spectra and signal counts of the photoionized neutrals from GaAs (100) and Au are compared to those of the secondary ions. While clusters larger than dimers are more efficiently detected as secondary ions, certain species, such as $\mathrm{As}_{2}$, $\mathrm{Au}$ and $\mathrm{Au}_{2}$, are preferentially detected through the neutral channel. Continuously tuning the photon wavelength allows PIE curves to be obtained for sputtered $\mathrm{As}_{\mathrm{m}}(\mathrm{m}=1,2)$ and $\mathrm{Au}_{\mathrm{n}}(\mathrm{n}=1-4)$. From the observed ionization thresholds, sputtered neutral As and Au show no clear evidence of electronic excitation, while neutral clusters have photoionization onsets shifted to lower energies by $\sim 0.3 \mathrm{eV}$. These shifts are attributed to unresolved vibrational and rotational excitations. High-spatial resolution chemical imaging with synchrotron VUV post-ionization was demonstrated at two different photon energies using a copper TEM grid embedded in indium. (Figure 14) The resulting images are used to illustrate the use of tunable VUV light for verifying mass peak assignments by exploiting the unique wavelength-dependent PIE of each sputtered neutral species.

A major thrust of the imaging program is to visualize organic molecules prevalent in plants and organisms that are being considered for biofuel development. Lignin is the second most abundant organic biopolymer in nature, and its association with cellulose places critical limitations on the rate, productivity and cost efficiency of sugar extraction from cellulosic biomass. ${ }^{80}$ Despite its importance, the details of the biosynthesis of lignin remain unknown, and 
the specific chemical changes that occur after genetically modifying plants are not completely clear. $^{81}$ It is therefore important to be able to image the spatial localization of lignin and its key intermediates. Lignin is made up of three primary subunits, or monolignols (sinapyl alcohol, coniferyl alcohol and p-coumaroyl alcohol), and exploratory experiments on the pure compounds have shown promising signs of intact parent molecules with the VUV-SNMS method. VUVSNMS signals are observed for numerous organic samples, i.e. polycyclic aromatic hydrocarbons (coronene, chrysene, etc.), amino acids (phenylalanine, asparagine, etc.), various DNA bases (adenine, thymine, cytosine), and other biologically relevant compounds such as coniferyl alcohol. ${ }^{82}$ The resulting mass spectra show VUV-SNMS signals with lower absolute counts compared to the corresponding SIMS signals, however there is reduced fragmentation of parent molecules in VUV-SNMS. For two molecules studied with SNMS, tryptophan and thymine, photoionization efficiency curve analysis of the parent molecule and prominent fragments suggest internal energies of $\sim 2 \mathrm{eV}$. The ionization energy onset of the parent molecules tend not to shift with increase in internal energy, in agreement with results obtained previously with thermally desorbed biomolecules, ${ }^{64}$ However, fragments formed by dissociative photoionization do show remarkable shifts in appearance energy upon an increase of the internal energy of the neutral molecule. ${ }^{82}$ Understanding the dissociative photoionization pathways of these molecules as a function of internal energy that is deposited in the sputtering step, coupled with analysis of fragmentation pathways as a function of photon energy is a necessary first step towards successful application of imaging mass spectroscopy to biological and organic molecular systems. 


\section{Synchrotron and Free Electron Laser Science of the Future}

While synchrotron beamlines provide remarkable new insights into reactive dynamics, heterogeneous chemistry, thermochemistry, and spectroscopy, few experiments take advantage of the time structure of the synchrotron. Most measurements utilize the nearly quasi-continuous output of the synchrotron for static measurements or to monitor more slowly varying time sampling. At a typical synchrotron the electron bunch structure provides pulses of radiation at very high repetition rates, e.g. $500 \mathrm{MHz}$. Although not ideal for two-color experiments because of the mismatch with the repetition rate of lasers, low repetition rate lasers (e.g. $1 \mathrm{kHz}$ ) have been merged with the synchrotron to produce some two color or pump-probe types of measurements. ${ }^{83-85}$

At major facilities of the future, typically involving the principle of free electron laser (FEL) outputs, ${ }^{86}$ the electron emittence is low enough and the undulator emission is high enough to produce laser-like gain over a long undulator path length. Time dynamics and coherence properties will become major new ways to access dynamics in the vacuum ultraviolet, soft X-ray, and hard X-ray regimes. Already the FEL at Hamburg (FLASH) has been operational, and atomic and molecular scientists are among the first users to study multiple ionization events. ${ }^{87}$ At Stanford (LCLS), millijoule outputs at $30 \mathrm{~Hz}$ repetition rates are enabling first experiments on core hole dynamics, and the radiation pulses will be applied in pump-probe configurations on

solutions and for coherent imaging of molecular structures. ${ }^{88}$ In Figure 15, a concept ${ }^{89}$ is shown for a very high repetition rate superconducting linac free electron laser facility that will allow multiple FELs to be supported by beam steering of the electron bunches, providing $10-100 \mathrm{kHz}$ repetition rates across the whole UV to soft X-ray spectrum. With specialized laser 
microbunching, ${ }^{90}$ or seeding, attosecond and femtosecond pulses will be achievable in some beam lines, while longer pulse high resolution outputs will be possible at the same facility.

A whole new paradigm of ultrafast and even attosecond time dynamics measurements is envisioned at free electron laser facilities, offered by the merger of pulsed lasers with FEL outputs. In valence electron dynamics, tunable vacuum ultraviolet light may be able to probe changes in orbital electron densities in real time, and core level spectroscopies will be seminal in following the chemical environment of specific atoms subjected to time-varying potential surface interactions. In the hard X-ray, time-resolved diffraction will become a benchmark experiment, and coherent diffractive imaging will reveal structures in real time. Physical chemists and chemical physicists will play significant roles in chemical dynamics measurements at these new facilities.

\section{Acknowledgements}

The authors gratefully acknowledge support from the Director, Office of Energy Research, Office of Basic Energy Sciences, Chemical Sciences Division of the U.S. Department of Energy under contract No. DE-AC02-05CH11231. The support of planetary atmosphere research by the National Aeronautics and Space Administration (Grant No. NNX09AB60G) is gratefully acknowledged. Leone gratefully acknowledges additional support for his research in related areas of investigation from the National Science Foundation, the Air Force Office of Scientific Research, the Keck Foundation, and the National Security Science and Engineering Faculty Fellowship program.

The authors are grateful to David Osborn, Jia Zhou, Lynelle Takahashi, Oleg Kostko, Hiroshi Imanaka and John Corlett for providing figures and valuable discussions regarding this article. 


\section{References}

1 R. D. Levine, Molecular Reaction Dynamics, Cambridge University Press, 2005.

2 C. A. Taatjes and J. F. Hershberger, Annu. Rev. Phys. Chem., 2001, 52, 41-70.

3 J. J. Valentini, Annu. Rev. Phys. Chem., 2001, 52, 15-39.

4 P. Casavecchia, F. Leonori, N. Balucani, R. Petrucci, G. Capozza and E. Segoloni, Phys. Chem. Chem. Phys., 2009, 11, 46-65.

5 M. Dantus and V. V. Lozovoy, Chem. Rev., 2004, 104, 1813-1859.

6 F. Krausz and M. Ivanov, Rev. Mod. Phys., 2009, 81, 163-234.

7 A. McIlroy and G. McRae, et al., Basic Research Needs for Clean and Efficient Combustion of 21st Century Transportation Fuels, Department of Energy, Office of Science, 2006.

8 D. J. Jacob, et al., Radiative Forcing of Climate Change: Expanding the Concept and Addressing Uncertainties, D. C. National Academies Press, 2005.

9 W. E. Moerner, Proc. Nat. Acad. Sci., 2007, 104, 15584-15584.

10 C. Ringemann, B. Harke, C. von Middendorff, R. Medda, A. Honigmann, R. Wagner, M. Leutenegger, A. Schonle, S. W. Hell and C. Eggeling, New J. Phys., 2009, 11, 103054.

11 B. Huang, M. Bates and X. W. Zhuang, Ann. Rev. Biochem., 2009, 78, 993-1016.

12 C. Bustamante, Annu. Rev. Biochem., 2008, 77, 45-50.

13 K. Wille, Rep. Prog. Phys., 1991, 54, 1005-1068.

14 X. Yang, J. Lin, Y. T. Lee, D. A. Blank, A. G. Suits and A. M. Wodtke, Rev. Sci. Instrum., 1997, 68, 3317-3326.

15 C. W. Hsu, K. T. Lu, M. Evans, Y. J. Chen, C. Y. Ng and P. Heimann, J. Chem. Phys., 1996, 105, 3950-3961. 
16 A. G. Suits, P. Heimann, X. M. Yang, M. Evans, C. W. Hsu, K. T. Lu, Y. T. Lee and A. H. Kung, Rev. Sci. Instrum., 1995, 66, 4841-4844.

17 D. L. Osborn, P. Zou, H. Johnsen, C. C. Hayden, C. A. Taatjes, V. D. Knyazev, S. W. North, D. S. Peterka, M. Ahmed and S. R. Leone, Rev. Sci. Instrum., 2008, 79, 104103

18 J. N. Shu, K. R. Wilson, M. Ahmed and S. R. Leone, Rev. Sci. Instrum., 2006, 77, 043106.

19 T. A. Cool, K. Nakajima, T. A. Mostefaoui, F. Qi, A. McIlroy, P. R. Westmoreland, M. E. Law, L. Poisson, D. S. Peterka and M. Ahmed, J. Chem. Phys., 2003, 119, 8356-8365.

20 J. M. Byrd, Nucl. Instrum. Meth. Phys. Rev. Res. A, 1999, 427, 614-621.

21 http://xdb.lbl.gov/Section2/Sec 2-2.html.

22 P. A. Heimann, M. Koike, C. W. Hsu, D. Blank, X. M. Yang, A. G. Suits, Y. T. Lee, M. Evans, C. Y. Ng, C. Flaim and H. A. Padmore, Rev. Sci. Instrum., 1997, 68, 1945-1951.

23 R. C. Shiell, M. Evans, S. Stimson, C. W. Hsu, C. Y. Ng and J. W. Hepburn, Phys. Rev. Lett., 1998, 80, 472-475.

24 M. Evans, C. Y. Ng, C. W. Hsu and P. Heimann, J. Chem. Phys., 1997, 106, 978-981.

25 J. W. Keister, T. Baer, M. Evans, C. Y. Ng and C. W. Hsu, J. Phys. Chem. A, 1997, 101, 1866-1872.

26 P. M. Mayer, J. W. Keister, T. Baer, M. Evans, C. Y. Ng and C. W. Hsu, J. Phys. Chem. A, 1997, 101, 1270-1276.

27 R. A. Dressler, Y. Chiu, D. J. Levandier, X. N. Tang, Y. Hou, C. Chang, C. Houchins, H. Xu and C. Y. Ng, J. Chem. Phys., 2006, 125, 132306.

28 N. de Oliveira, D. Joyeux, D. Phalippou, J. C. Rodier, F. Polack, M. Vervloet and L. Nahon, Rev. Sci. Instrum., 2009, 80, 043101. 
29 D. A. Blank, N. Hemmi, A. G. Suits and Y. T. Lee, Chem. Phys., 1998, 231, 261-278.

30 D. A. Blank, A. G. Suits, Y. T. Lee, S. W. North and G. E. Hall, J. Chem. Phys., 1998, 108, 5784-5794.

31 C. A. Taatjes, N. Hansen, D. L. Osborn, K. Kohse-Hoinghaus, T. A. Cool and P. R. Westmoreland, Phys. Chem. Chem. Phys., 2008, 10, 20-34.

32 A. J. Miles, S. V. Hoffmann, Y. Tao, R. W. Janes and B. A. Wallace, Spectrosc., 2007, 21, 245-255.

33 R. L. Cavasso, M. G. P. Homen, P. T. Fonseca and A. N. de Brito, Rev. Sci. Instrum., 2007, 78, 115104.

34 R. B. Metz, C. Nicolas, M. Ahmed and S. R. Leone, J. Chem. Phys., 2005, 123, 114313.

35 C. Nicolas, J. N. Shu, D. S. Peterka, M. Hochlaf, L. Poisson, S. R. Leone and M. Ahmed, J. Am. Chem. Soc., 2006, 128, 220-226.

36 O. Kostko, M. Ahmed and R. B. Metz, J. Phys. Chem. A, 2009, 113, 1225-1230.

37 L. Belau, S. E. Wheeler, B. W. Ticknor, M. Ahmed, S. R. Leone, W. D. Allen, H. F. Schaefer and M. A. Duncan, J. Am. Chem. Soc., 2007, 129, 10229-10243.

38 O. Kostko, S. R. Leone, M. A. Duncan and M. Ahmed, J. Phys. Chem. A, 2010, 114, 3176-3181.

39 R. I. Kaiser, L. Belau, S. R. Leone, M. Ahmed, Y. M. Wang, B. J. Braams and J. M. Bowman, Chemphyschem, 2007, 8, 1236-1239.

40 R. I. Kaiser, O. Kostko, A. M. Mebel and M. Ahmed, Chem. Phys. Lett., 2010, 485, 281285.

41 M. Citir, R. B. Metz, L. Belau and M. Ahmed, J. Phys. Chem. A, 2008, 112, 9584-9590. 
42 O. Kostko, J. Zhou, B. J. Sun, J. S. Lie, A. H. H. Chang, R. I. Kaiser and M. Ahmed, 2010, Submitted.

43 L. Belau, K. R. Wilson, S. R. Leone and M. Ahmed, J. Phys. Chem. A, 2007, 111, $7562-$ 7568.

44 K. Bravaya, O. Kostko, M. Ahmed and A. I. Krylov, Phys. Chem. Chem. Phys., 2010, 12, 2292-2307.

45 O. Kostko, K. Bravaya, A. I. Krylov and M. Ahmed, Phys. Chem. Chem. Phys., 2010, DOI:10.1039/b921498d.

46 O. Kostko, S. K. Kim, S. R. Leone and M. Ahmed, J. Phys. Chem. A, 2009, 113, 1420614211.

47 N. Hansen, J. A. Miller, P. R. Westmoreland, T. Kasper, K. Kohse-Hoinghaus, J. Wang and T. A. Cool, Combust. Flame, 2009, 156, 2153-2164.

48 N. Hansen, T. A. Cool, P. R. Westmoreland and K. Kohse-Hoinghaus, Prog. Energy Combust. Sci., 2009, 35, 168-191.

49 T. A. Cool, A. McIlroy, F. Qi, P. R. Westmoreland, L. Poisson, D. S. Peterka and M. Ahmed, Rev. Sci. Instrum., 2005, 76, 94102.

50 A. C. Alkidas, Energy Conv. Manag., 2007, 48, 2751-2761.

51 A. K. Agarwal, Prog. Energy Combust. Sci., 2007, 33, 233-271.

52 C. A. Taatjes, N. Hansen, A. McIlroy, J. A. Miller, J. P. Senosiain, S. J. Klippenstein, F. Qi, L. S. Sheng, Y. W. Zhang, T. A. Cool, J. Wang, P. R. Westmoreland, M. E. Law, T. Kasper and K. Kohse-Hoinghaus, Science, 2005, 308, 1887-1889.

53 P. Osswald, U. Struckmeier, T. Kasper, K. Kohse-Hoinghaus, J. Wang, T. A. Cool, N. Hansen and P. R. Westmoreland, J. Phys. Chem. A, 2007, 111, 4093-4101. 
54 G. Meloni, T. M. Selby, D. L. Osborn and C. A. Taatjes, J. Phys. Chem. A, 2008, 112, 13444-13451.

55 C. A. Taatjes, G. Meloni, T. M. Selby, A. J. Trevitt, D. L. Osborn, C. J. Percival and D. E. Shallcross, J. Am. Chem. Soc., 2008, 130, 11883-11885.

56 G. Meloni, T. M. Selby, F. Goulay, S. R. Leone, D. L. Osborn and C. A. Taatjes, J. Am. Chem. Soc., 2007, 129, 14019-14025.

57 G. Meloni, P. Zou, S. J. Klippenstein, M. Ahmed, S. R. Leone, C. A. Taatjes and D. L. Osborn, J. Am. Chem. Soc., 2006, 128, 13559-13567.

58 F. Goulay, D. L. Osborn, C. A. Taatjes, P. Zou, G. Meloni and S. R. Leone, Phys. Chem. Chem. Phys., 2007, 9, 4291-4300.

59 F. Goulay, A. J. Trevitt, G. Meloni, T. M. Selby, D. L. Osborn, C. A. Taatjes, L. Vereecken and S. R. Leone, J. Am. Chem. Soc., 2009, 131, 993-1005.

60 J. N. Shu, K. R. Wilson, M. Ahmed, S. R. Leone, C. Graf and E. Ruhl, J. Chem. Phys., $2006,124,34707$.

61 J. N. Shu, K. R. Wilson, A. N. Arrowsmith, M. Ahmed and S. R. Leone, Nano Lett., 2005, 5, 1009-1015.

62 K. R. Wilson, S. L. Zou, J. N. Shu, E. Ruhl, S. R. Leone, G. C. Schatz and M. Ahmed, Nano Lett., 2007, 7, 2014-2019.

63 K. R. Wilson, D. S. Peterka, M. Jimenez-Cruz, S. R. Leone and M. Ahmed, Phys. Chem. Chem. Phys., 2006, 8, 1884-1890.

64 K. R. Wilson, M. Jimenez-Cruz, C. Nicolas, L. Belau, S. R. Leone and M. Ahmed, J. Phys. Chem. A, 2006, 110, 2106-2113. 
65 E. Gloaguen, E. R. Mysak, S. R. Leone, M. Ahmed and K. R. Wilson, Int. J. Mass

Spectrom., 2006, 258, 74-85.

66 J. D. Smith, J. H. Kroll, C. D. Cappa, D. L. Che, C. L. Liu, M. Ahmed, S. R. Leone, D. R. Worsnop and K. R. Wilson, Atmos. Chem. Phys., 2009, 9, 3209-3222.

67 D. L. Che, J. D. Smith, M. Ahmed, S. R. Leone and K. R. Wilson, Phys. Chem. Chem. Phys, 2009, 11, 7885 - 7895.

68 S. Chakraborty, M. Ahmed, T. L. Jackson and M. H. Thiemens, Science, 2008, 321, $1328-1331$.

69 S. Chakraborty, M. Ahmed, T. L. Jackson and M. H. Thiemens, Science, 2009, 324, 1516-d.

70 H. Imanaka and M. A. Smith, Geophys. Res. Lett., 2007, 34, L02204.

71 H. Imanaka and M. A. Smith, J. Phys. Chem. A, 2009, 113, 11187-11194.

72 S. Lee, R. J. Hoobler and S. R. Leone, Rev. Sci. Instrum., 2000, 71, 1816-1823.

73 A. J. Trevitt, F. Goulay, G. Meloni, D. L. Osborn, C. A. Taatjes and S. R. Leone, Int. J. Mass Spectrom., 2009, 280, 113-118.

74 P. P. Lavvas, A. Coustenis and I. M. Vardavas, Planet. Spac. Sci., 2008, 56, 27-66.

75 A. J. Trevitt, F. Goulay, C. A. Taatjes, D. L. Osborn and S. R. Leone, J. Phys. Chem. A, 2010, 114, 1749-1755.

76 D. G. Castner and B. D. Ratner, Surf. Sci., 2002, 500, 28-60.

77 P. K. Quinn, T. S. Bates, D. J. Coffman and D. S. Covert, Atmos. Chem. Phys., 2008, 8, 1029-1042.

78 R. M. A. Heeren, D. F. Smith, J. Stauber, B. Kukrer-Kaletas and L. MacAleese, J. Am. Soc. Mass Spectrom., 2009, 20, 1006-1014. 
79 L. K. Takahashi, J. Zhou, K. R. Wilson, S. R. Leone and M. Ahmed, J. Phys. Chem. A, 2009, 113, 4035-4044.

$80 \quad$ H. Hisano, In Vitro Cell. Dev. Biol. Plant, 2009, 45, 306-313.

81 J. M. Humphreys and C. Chapple, Curr. Opinion Plant Biol., 2002, 5, 224-229.

82 J. Zhou, L. K. Takahashi, K. R. Wilson, S. R. Leone and M. Ahmed, 2010, submitted.

83 L. Young, D. A. Arms, E. M. Dufresne, R. W. Dunford, D. L. Ederer, C. Hohr, E. P. Kanter, B. Krassig, E. C. Landahl, E. R. Peterson, J. Rudati, R. Santra and S. H. Southworth, Phys. Rev. Lett., 2006, 97, 083601.

84 J. Plenge, C. Nicolas, A. G. Caster, M. Ahmed and S. R. Leone, J. Chem. Phys., 2006, 125, 133315.

85 C. Y. Ng, J. Electron Spec. Rel. Phenom., 2005, 142, 179-192.

86 S. Khan, J. Mod. Opt., 2008, 55, 3469-3512.

87 C. Bostedt, H. N. Chapman, J. T. Costello, J. R. Crespo López-Urrutia, S. Düsterer, S. W. Epp, J. Feldhaus, A. Föhlisch, M. Meyer, T. Möller, R. Moshammer, M. Richter, K. SokolowskiTinten, A. Sorokin, K. Tiedtke, J. Ullrich and W. Wurth, Nucl. Instrum. Meth. A, 2009, 601, 108122.

88 H. N. Chapman, A. Barty, M. J. Bogan, S. Boutet, M. Frank, S. P. Hau-Riege, S. Marchesini, B. W. Woods, S. Bajt, H. Benner, R. A. London, E. Plonjes, M. Kuhlmann, R. Treusch, S. Dusterer, T. Tschentscher, J. R. Schneider, E. Spiller, T. Moller, C. Bostedt, M. Hoener, D. A. Shapiro, K. O. Hodgson, D. Van der Spoel, F. Burmeister, M. Bergh, C. Caleman, G. Huldt, M. M. Seibert, F. Maia, R. W. Lee, A. Szoke, N. Timneanu and J. Hajdu, Nat. Phys., 2006, 2, 839-843.

89 http://newscenter.lbl.gov/feature-stories/2009/12/21/accelerators-tomorrow-part1/. 
90 S. M. Gullans, J. S. Wurtele, G. Penn and A. A. Zholents, Opt. Commun., 2007, 274, 167.

\section{Figure Captions}

Figure 1: Photograph of the Advanced Light Source (domed building), a synchrotron located in Berkeley.

Figure 2: Photograph of the Chemical Dynamics Beamline undulator and part of the storage ring.

Figure 3: Photograph of a typical end-station at the Chemical Dynamics Beamline. Shown is the multiplexed chemical kinetic photoionization mass spectrometer with an excimer laser in the background.

Figure 4: Schematic of the Chemical Dynamics Beamline. T1 and T2 provide output from the raw undulator beam and have a flux of $10^{15}-10^{16}$ photons $\mathrm{s}^{-1}$ at $0.34 \mathrm{eV}$ nominal bandwidth. T3 and T4 provide monochromatized output with fluxes of $10^{12}-10^{14}$ photons $\mathrm{s}^{-1}$ with resolutions between 10-50 meV. T5 is a proposed terminal for both monochromatized and undulator beams. M1, M2, M3, M4X, and M7 are VUV reflecting mirrors, and the gas filter removes higher harmonics that are generated with the fundamental undulator beam. 
Figure 5: The top image shows a machine drawing of the source and VUV interaction chamber of the ablation apparatus. Bottom image is TOF spectra of ionized Si clusters optimized to various delays between the ablation laser pulse and pulsed valve delay.

Figure 6: Experimental photoionization efficiency curve for ${ }^{28} \mathrm{SiO}_{2}$. The experimental photoionization efficiency curve is the solid black line. The standard deviation in the experimental scans is shown as a wide gray line. A calculated photoelectron spectrum is shown as a black dotted line, and the integrated photoelectron spectrum generated a calculated photoionization efficiency curve which is shown as a black dashed line. The two horizontal lines denote the difference of $890 \mathrm{~cm}^{-1}$ between two peaks which are the electronically ground state of the cation and the first vibrational symmetric stretch of the cation. Adapted from and reproduced with permission from the American Chemical Society.

Figure 7: Synchrotron-MATI spectra of (a) $\mathrm{C}_{2} \mathrm{H}_{2}$, (b) $\mathrm{N}_{2} \mathrm{O}$, (c) $\mathrm{C}_{6} \mathrm{H}_{6}$, and (d) $\mathrm{H}_{2} \mathrm{O}$. Positions of vibration levels for cations of $\mathrm{C}_{2} \mathrm{H}_{2}$ and $\mathrm{N}_{2} \mathrm{O}$ are shown in (a) and (b). For nitrous oxide, the PIE curve is shown as a dashed line in (b). IE's for $\mathrm{C}_{6} \mathrm{H}_{6}$ and $\mathrm{H}_{2} \mathrm{O}$ are shown as arrows. Adapted and reproduced with permission from the American Chemical Society.

Figure 8: The flame sampling molecular beam mass spectrometer. MCP denotes microchannel plates. Radicals and stable neutral molecules are extracted out of a low pressure laminar flame using a quartz probe. The resulting molecular beam is photoionized using tunable VUV radiation produced by the Chemical Dynamics Beamline. A time of flight mass spectrum is 
obtained to examine concentration profiles of the fuel and its decomposition products. Reproduced with permission from the Royal Society of Chemistry.

Figure 9: Photoionization efficiency curves taken for $m / z=44$ ions sampled from four representative flames indicated in the figure. The fuel/oxygen equivalence ratio for each flame is denoted as $\phi$ in the figure. Photoion signals (circles) taken at the stated distance from the burner (indicated in $\mathrm{mm}$ in the figure) have been background-corrected and normalized by the measured photon flux. Signals are then scaled to computed mean photoionization cross sections (lines) for hypothetical mixtures of ethenol and acetaldehyde that give best fits to the data. Ionization energies for ethenol $\left(\mathrm{CH}_{2}=\mathrm{CHOH}\right)$ and acetaldehyde $\left(\mathrm{CH}_{3} \mathrm{CHO}\right)$ are indicated by the thin vertical lines. Reproduced with permission from the American Association of the Advancement of Science.

Figure 10: Tunable UV detection of kinetics and product species, illustrating three different types of correlations, mass versus photonionization photon energy at a specific time, mass versus time at a specific photon energy, and photoionization photon energy versus time at a specific mass. Reproduced with permission from American Institute of Physics.

Figure 11: Photoionization (PI) aerosol mass spectra of squalane measured at a photon energy of $10.2 \mathrm{eV}$ compared with a $70 \mathrm{eV}$ electron impact (EI) mass spectrum. 
Figure 12: The kinetic evolution of squalane $(\mathrm{Sq})$ and its first three reaction products in the presence of $\mathrm{O}_{2}\left(\mathrm{SqO}, \mathrm{SqO}_{2}, \mathrm{SqO}_{3}\right)$ as a function of $\mathrm{OH}$ exposure measured with VUV photoionization aerosol mass spectrometry.

Figure 13: (a) schematic of experimental apparatus used to perform photodissociation experiments in a windowless flow cell differentially pumped and coupled to the synchrotron. TPturbo pumps, QMS-quadrupole mass spectrometer, gv-gate valve, p-rotary mechanical pump. Mass spectra of gaseous products obtained with $60 \mathrm{~nm}$ irradiation of (b) a $\mathrm{N}_{2} / \mathrm{CH}_{4}$ ) $95 / 5$ gas mixture at a pressure of $0.11 \mathrm{mbar}$ and (c) pure $\mathrm{CH}_{4}$ gas at a pressure of 0.083 mbar. Top spectra in (b) and (c) are with VUV irradiation; spectra below in (b) and (c) are background caused by electron impact ionization. Adapted and reproduced with permission from the American Chemical Society.

Figure 14: VUV-SNMS images of indium (green) overlaid with copper (red) collected using 7.4 $\mathrm{eV}$ and $9.0 \mathrm{eV}$ photons. Each image is situated above their respective regions of the PIE curve. Images are collected using $\mathrm{Bi}_{3}{ }^{+}$primary ion with a spot size of $\sim 250 \mathrm{~nm}$, and a pulse length of $800 \mathrm{~ns}$; the results reflect a $200 \mu \mathrm{m}$ x $200 \mu \mathrm{m}$ area of the square copper TEM grid on indium ( $256 \times 256$ pixel raster, 21 scans, 550 s per data set).

Figure 15: Schematic of proposed free electron laser facility at LBNL, Berkeley. 


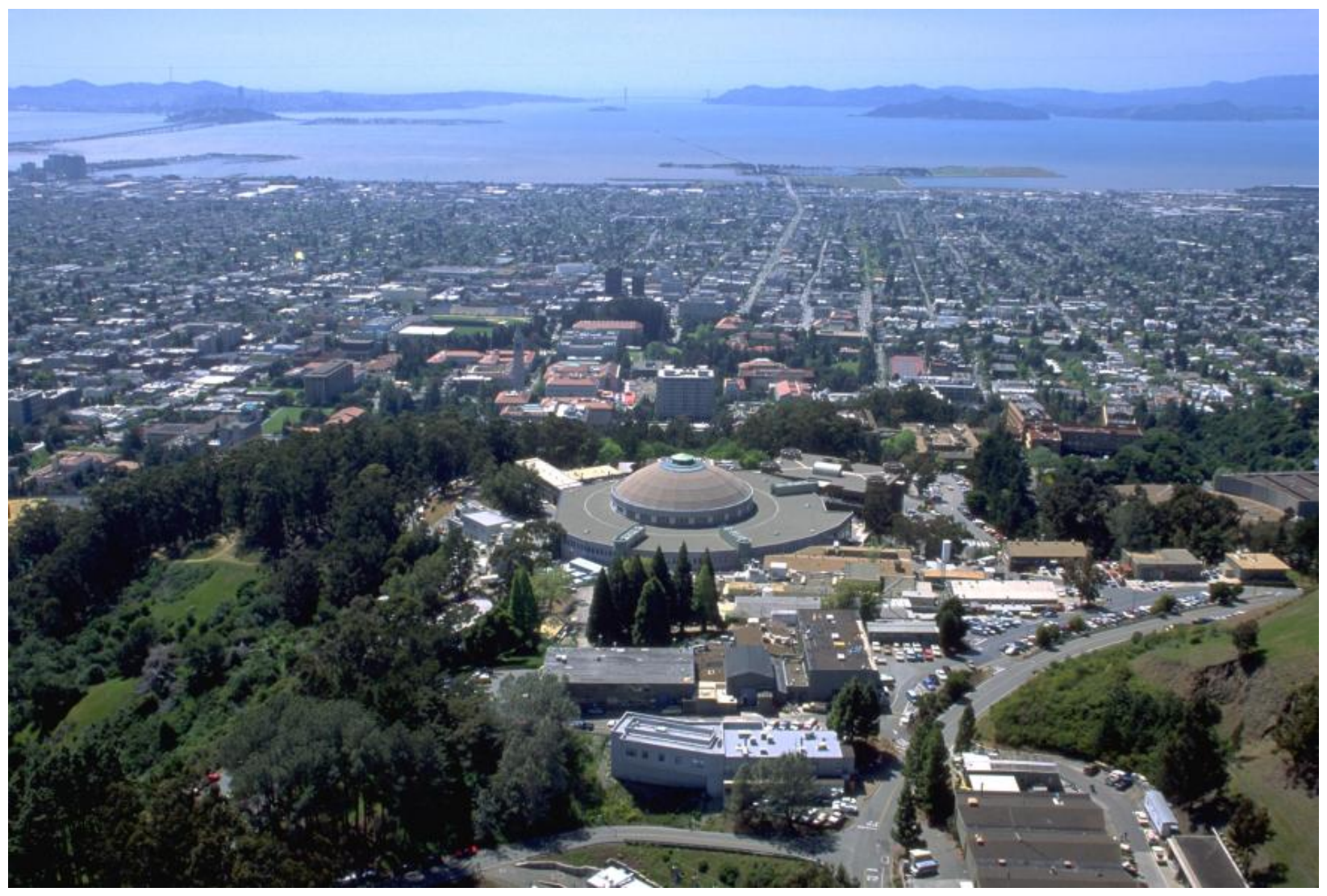

Figure 1 


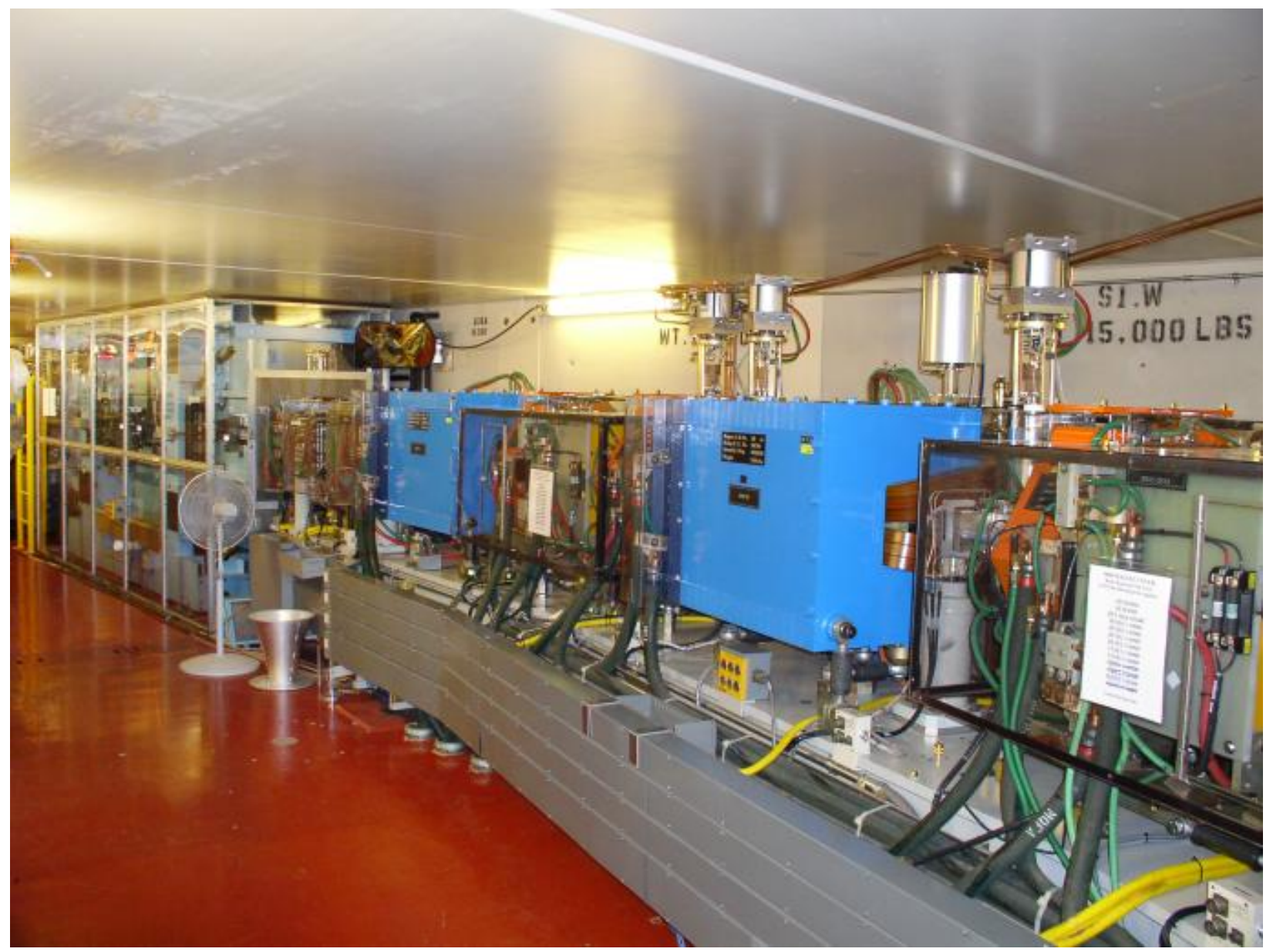

Figure 2 


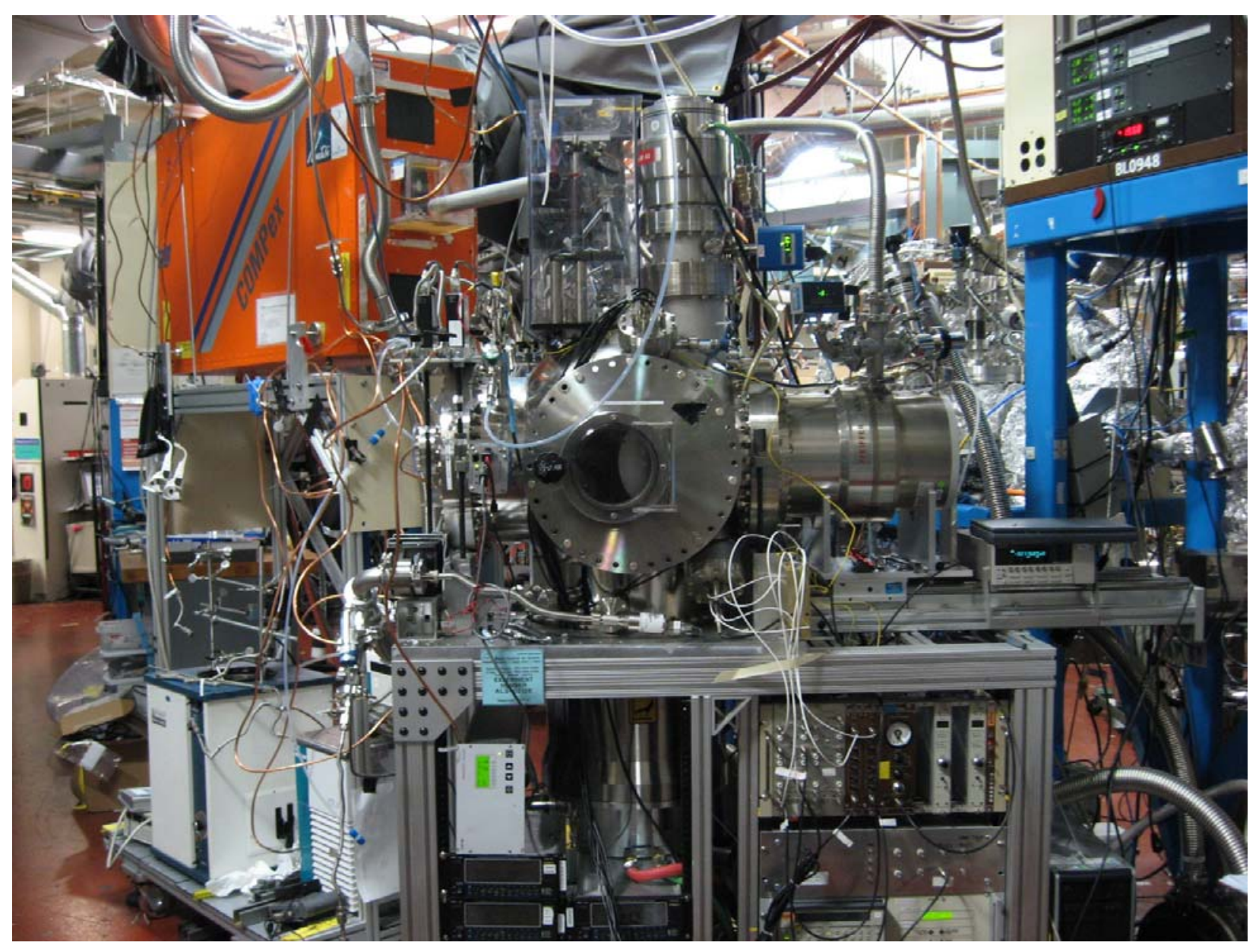

Figure 3 


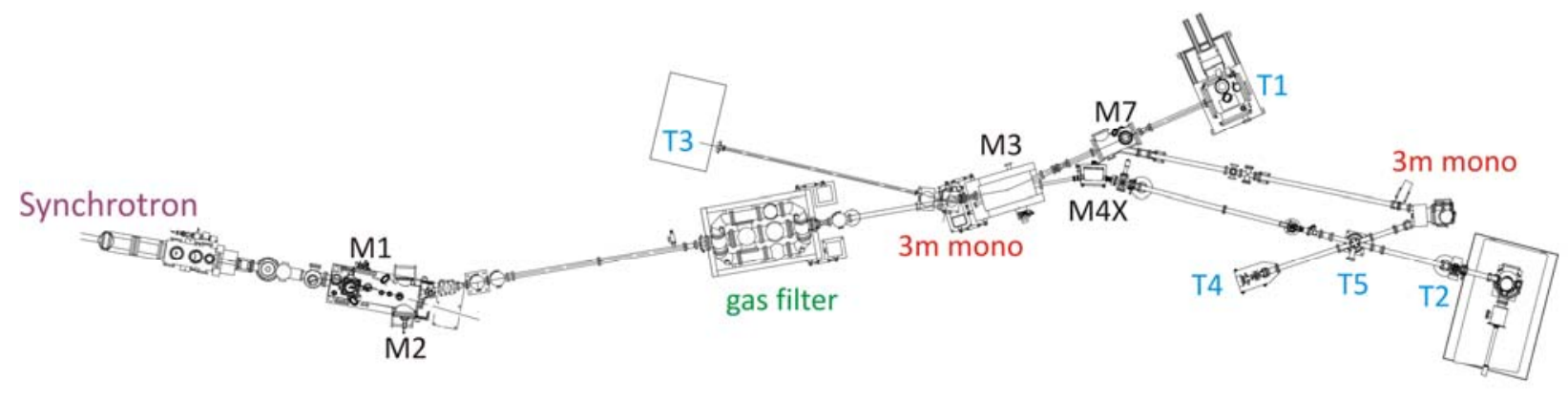

Figure 4 

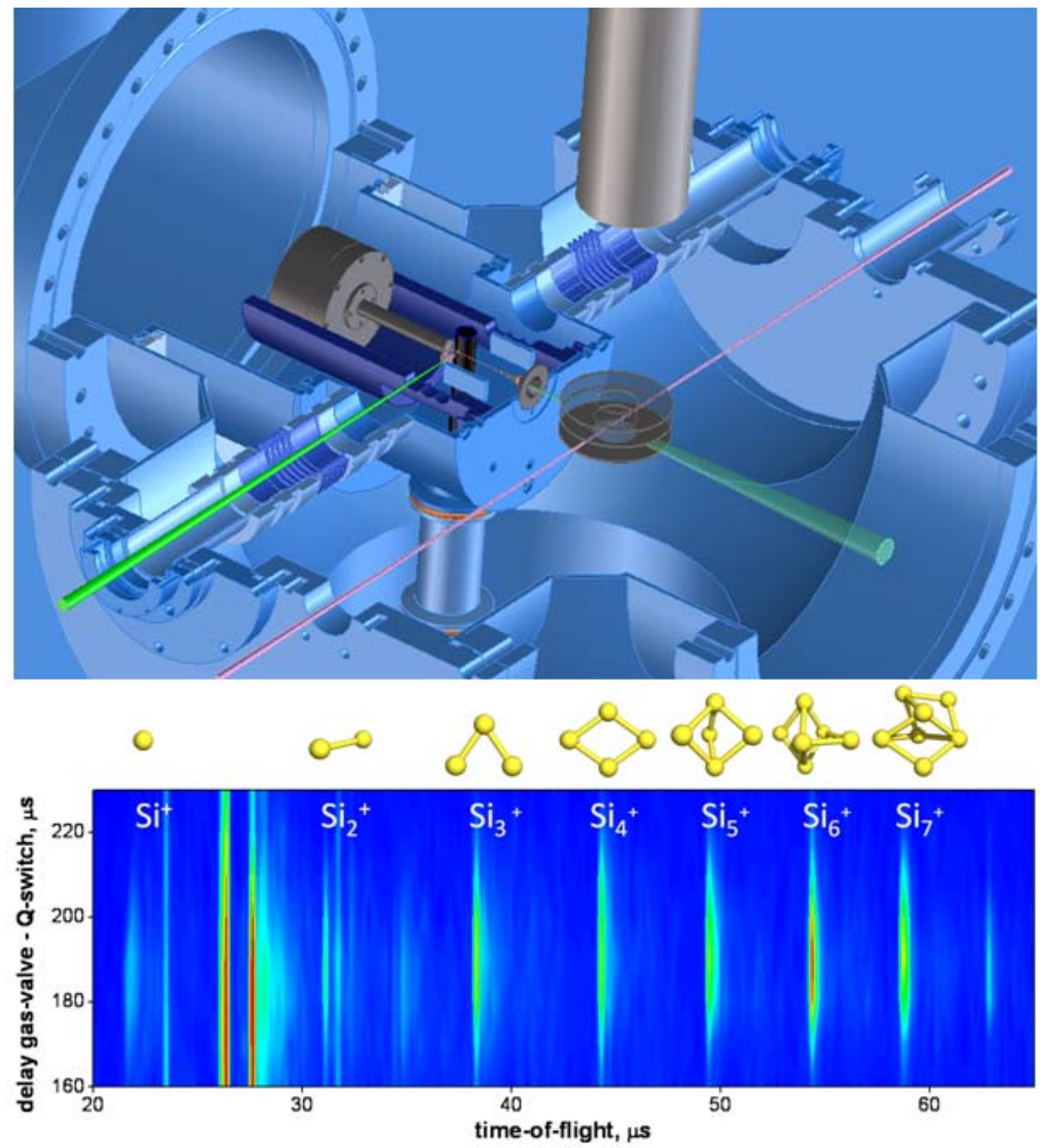

Figure 5 


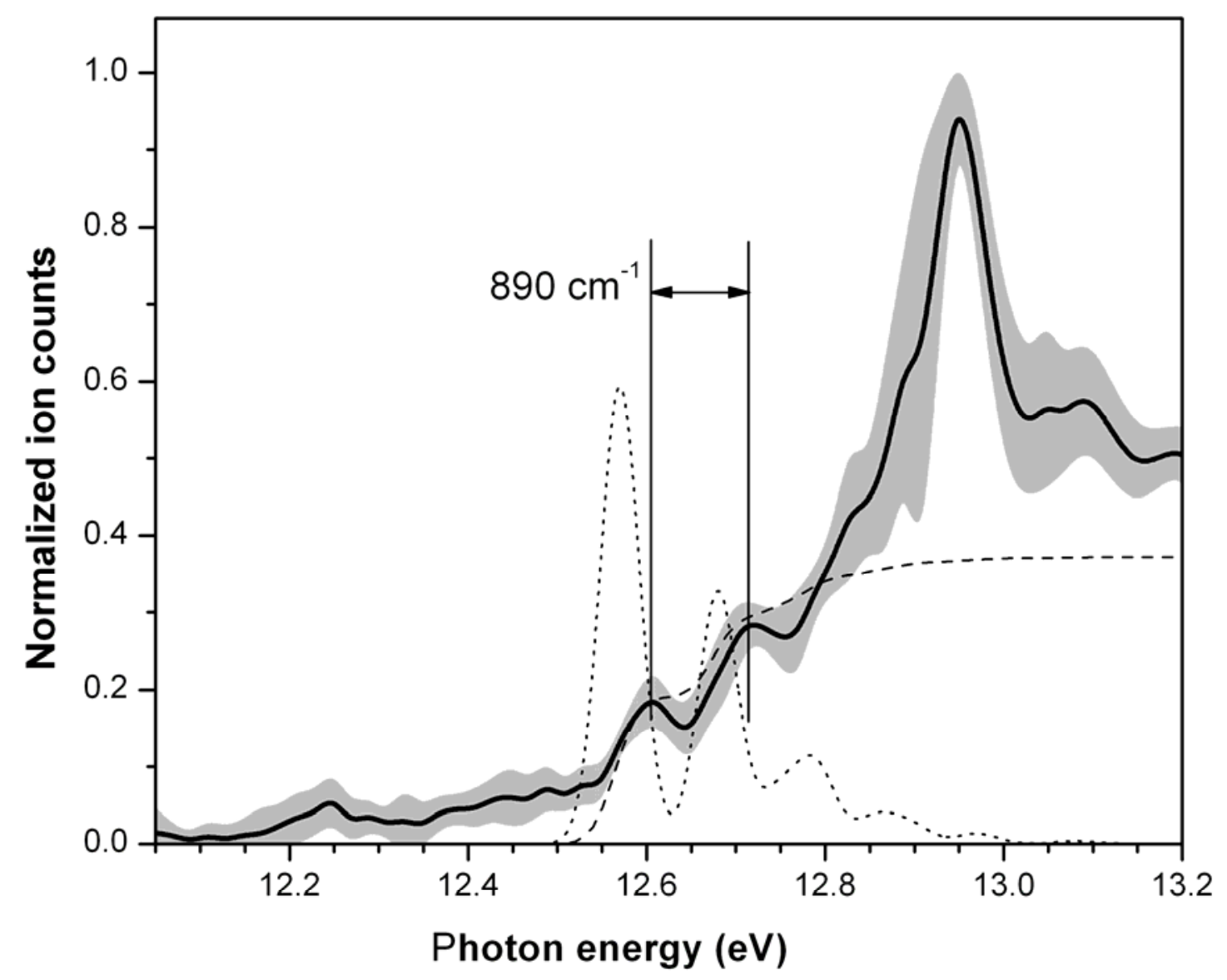

Figure 6 

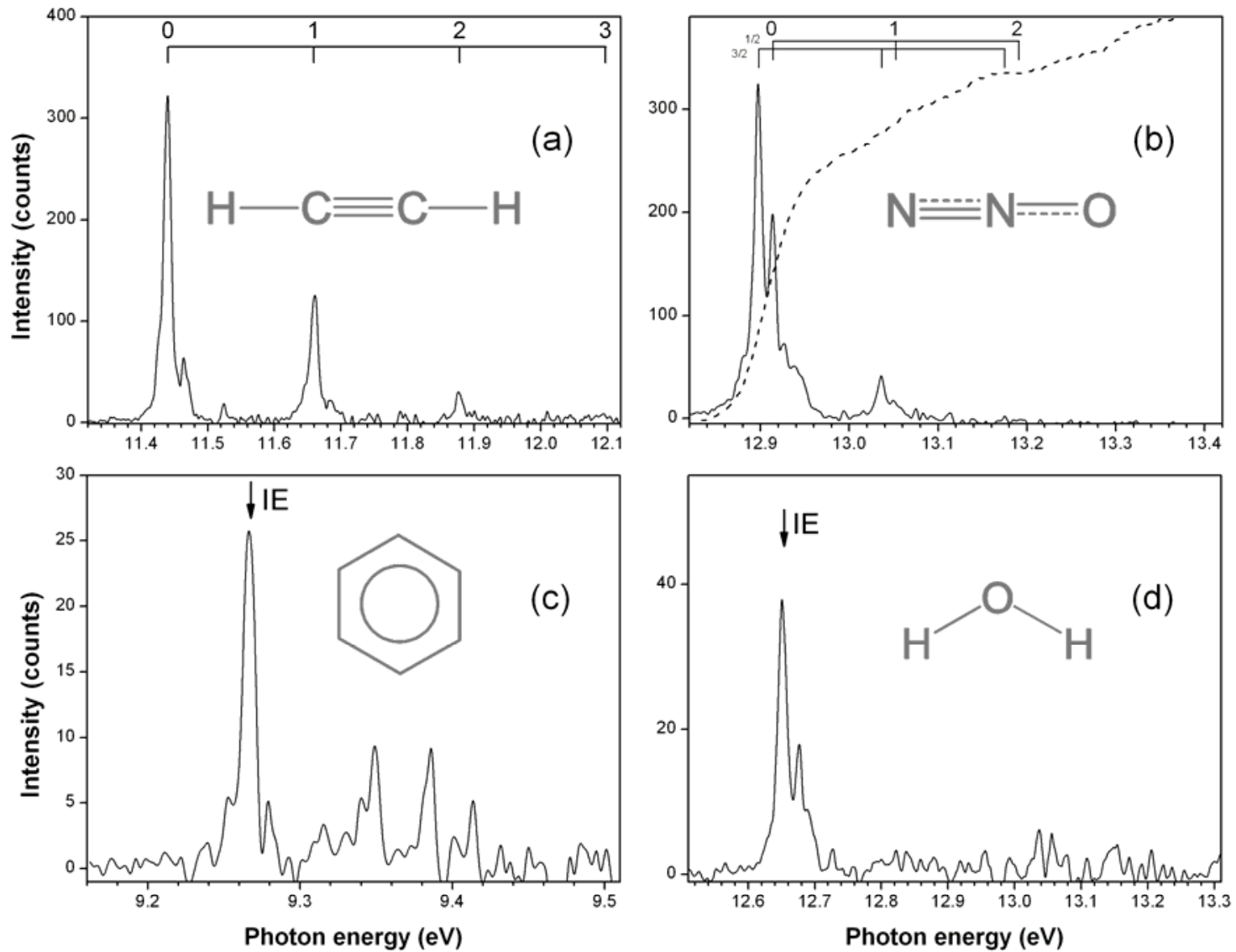

Figure 7 


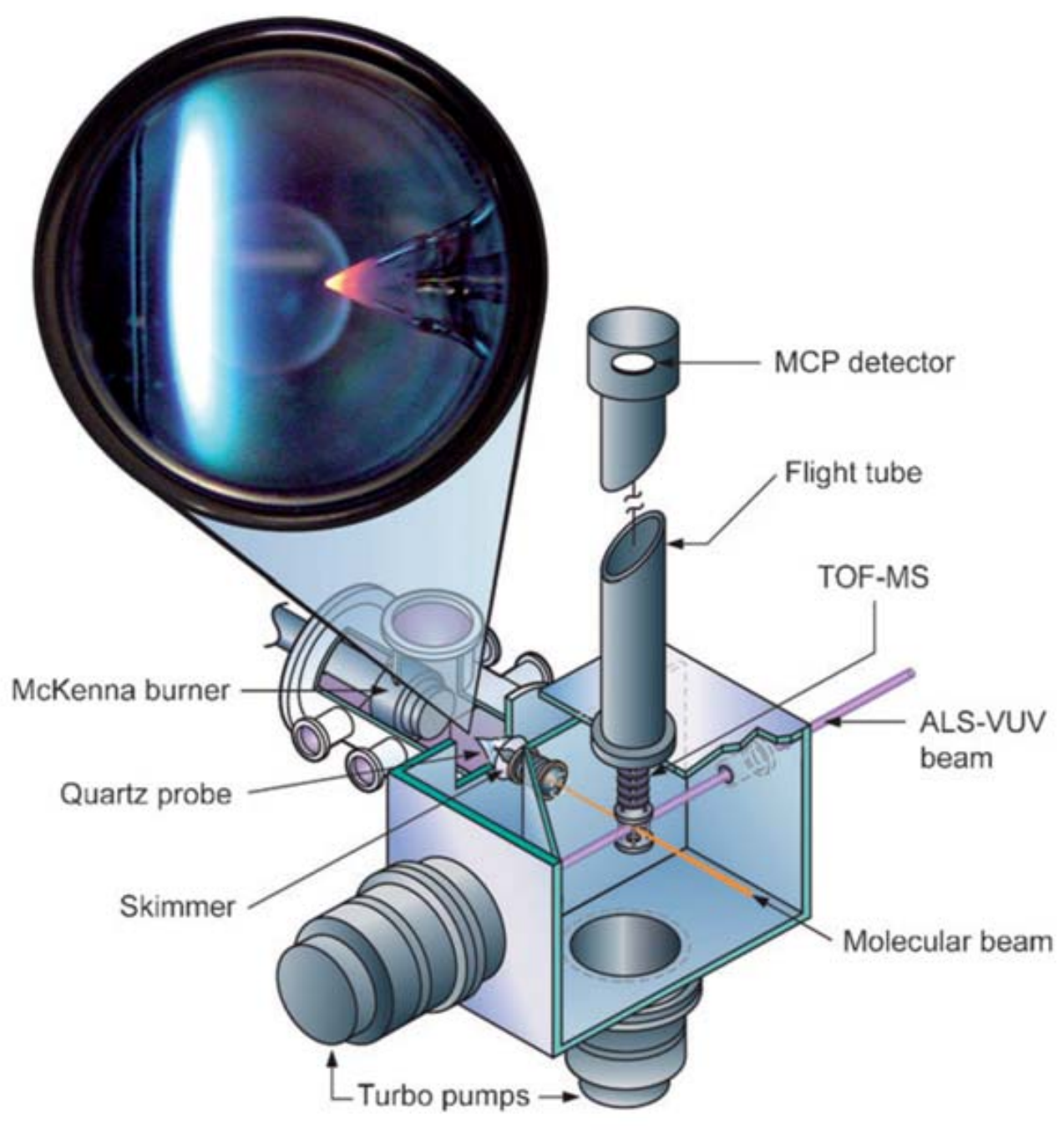

Figure 8 


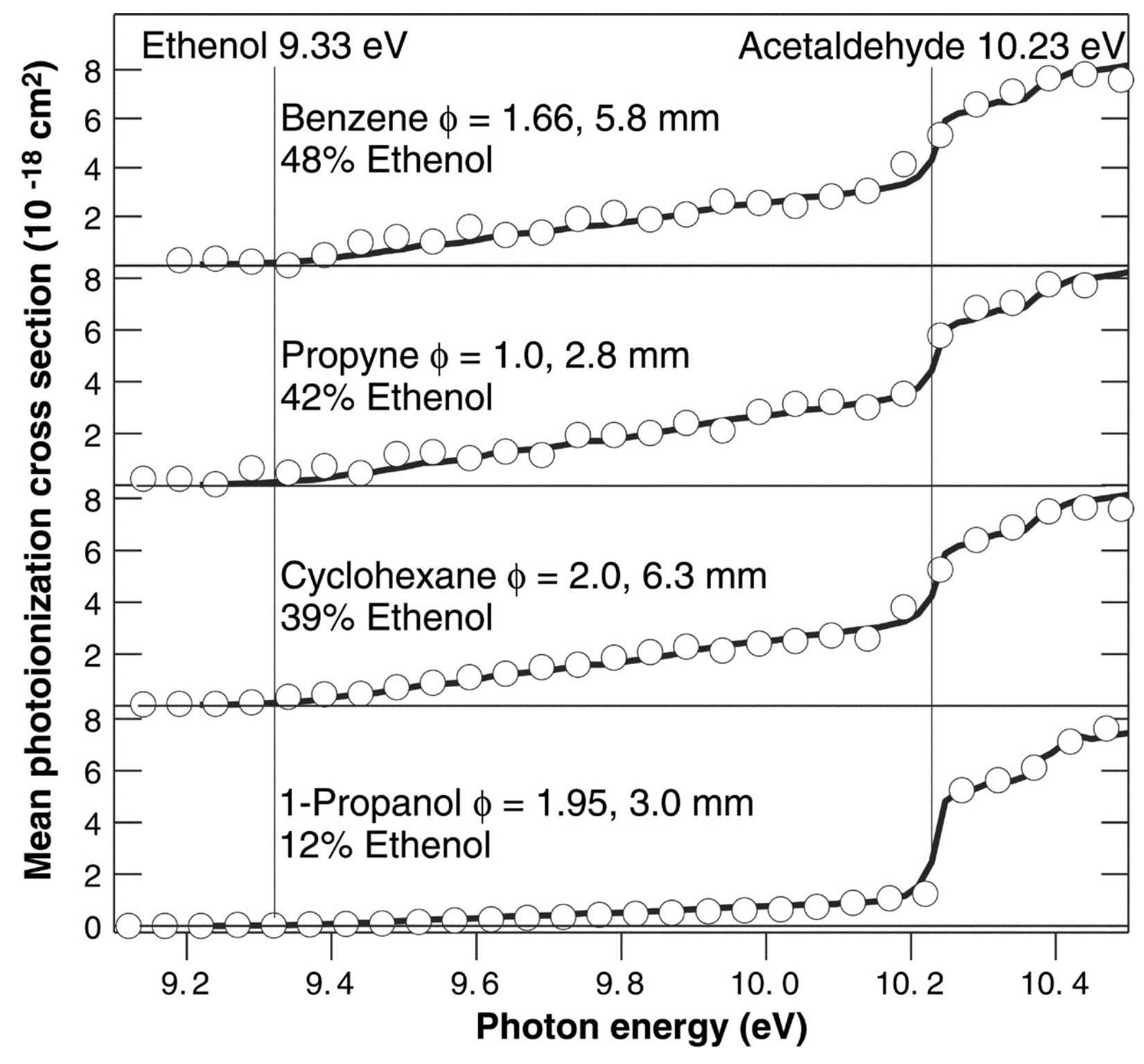

Figure 9 


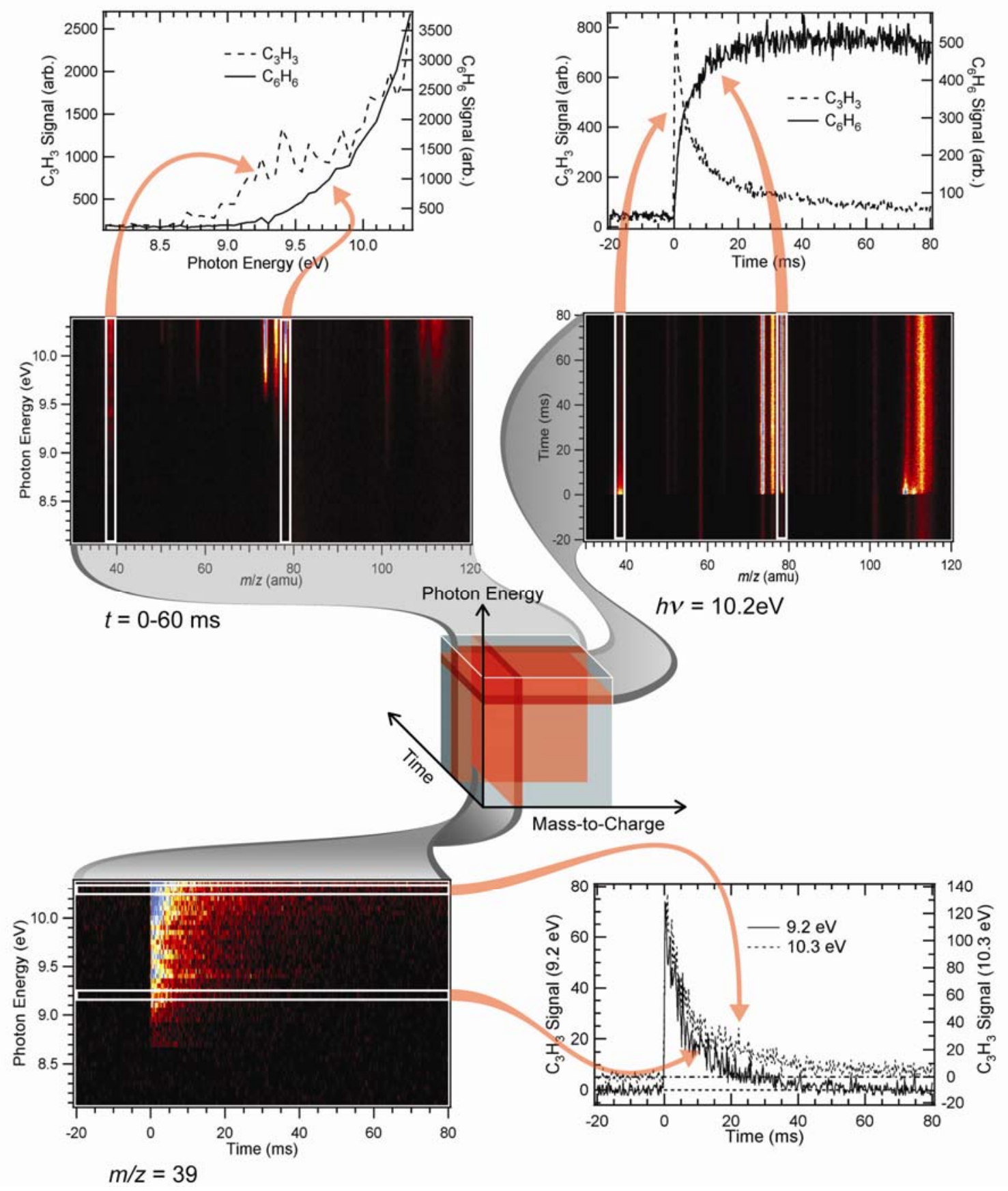

Figure 10 


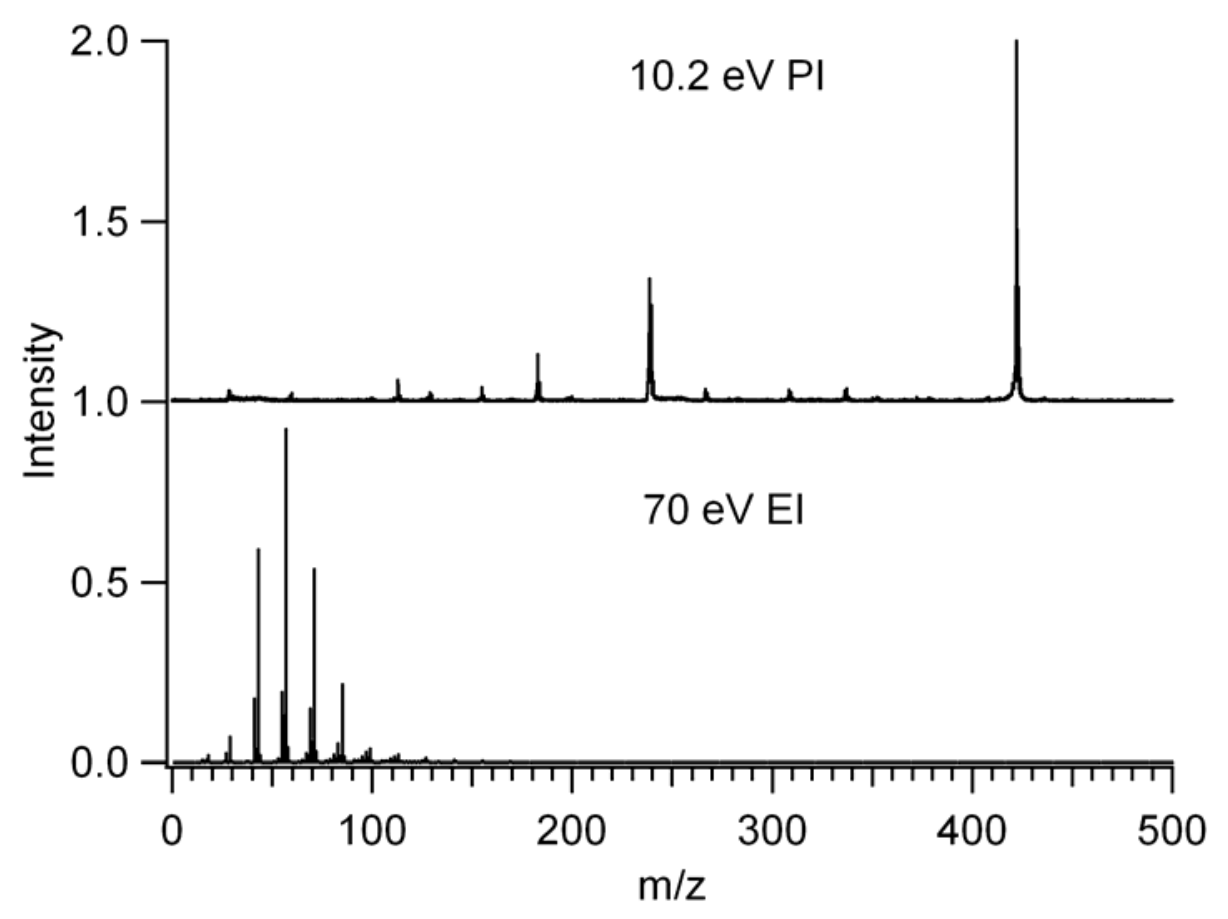

Figure 11 


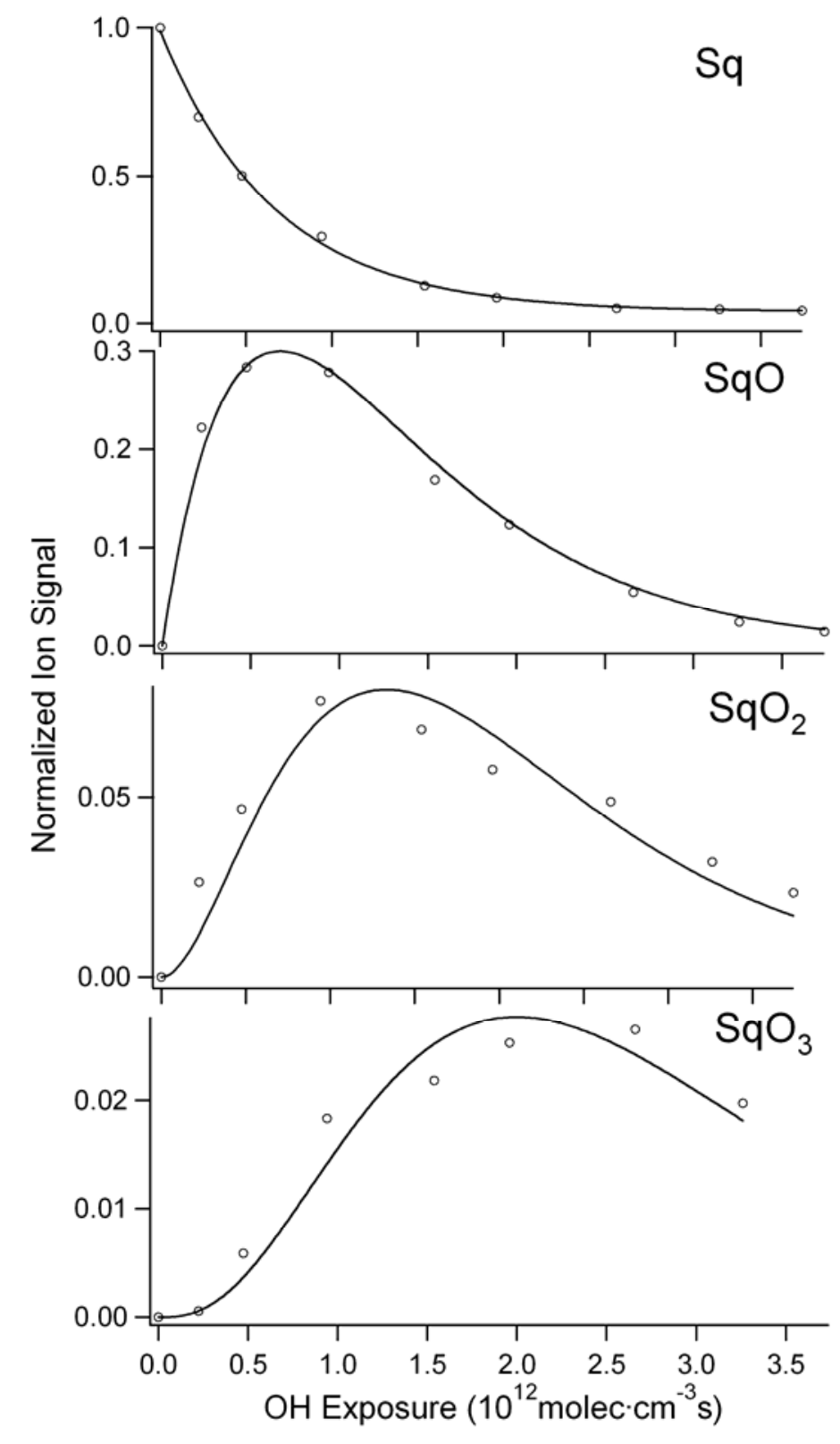

Figure 12 


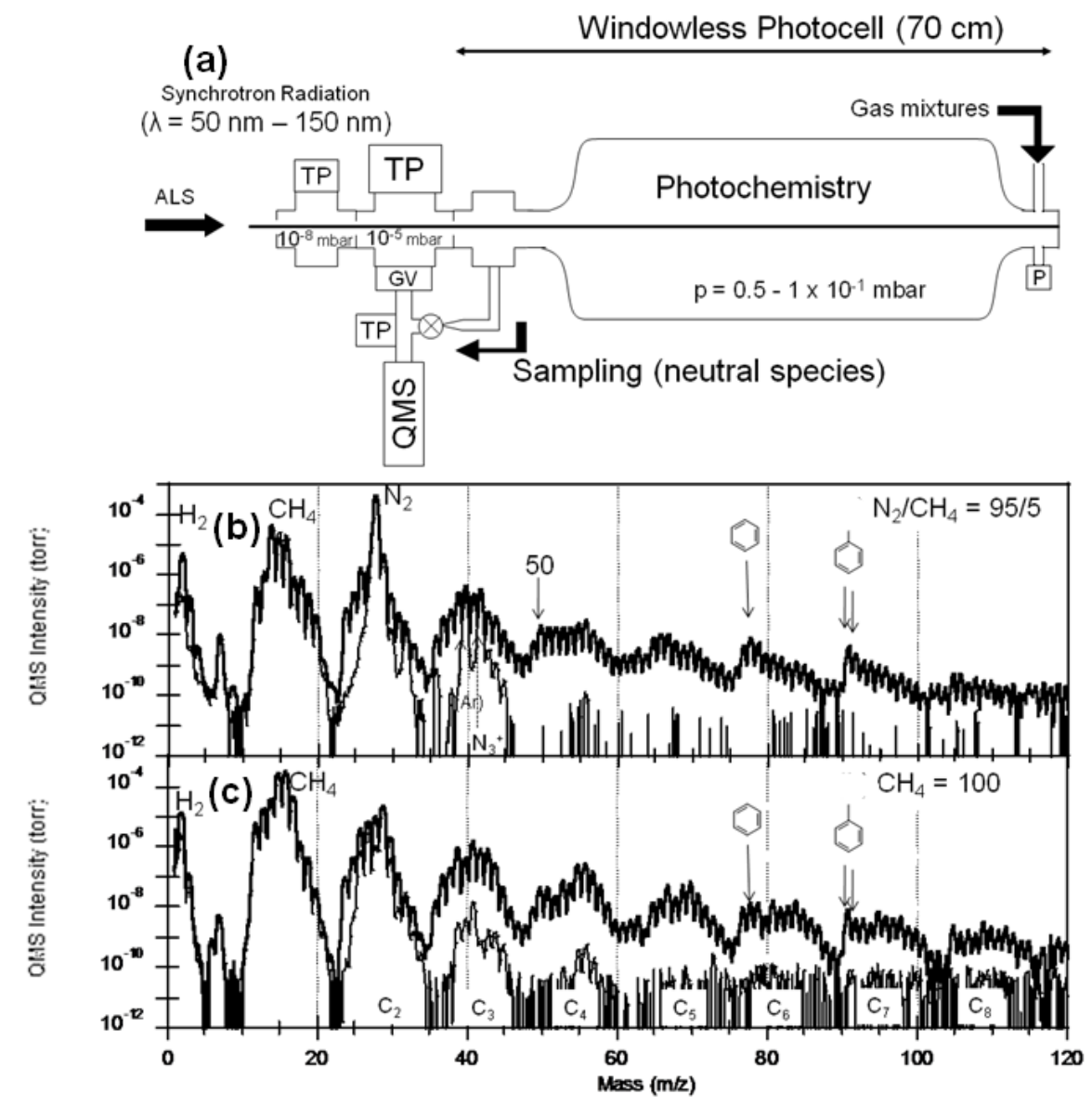

Figure 13 


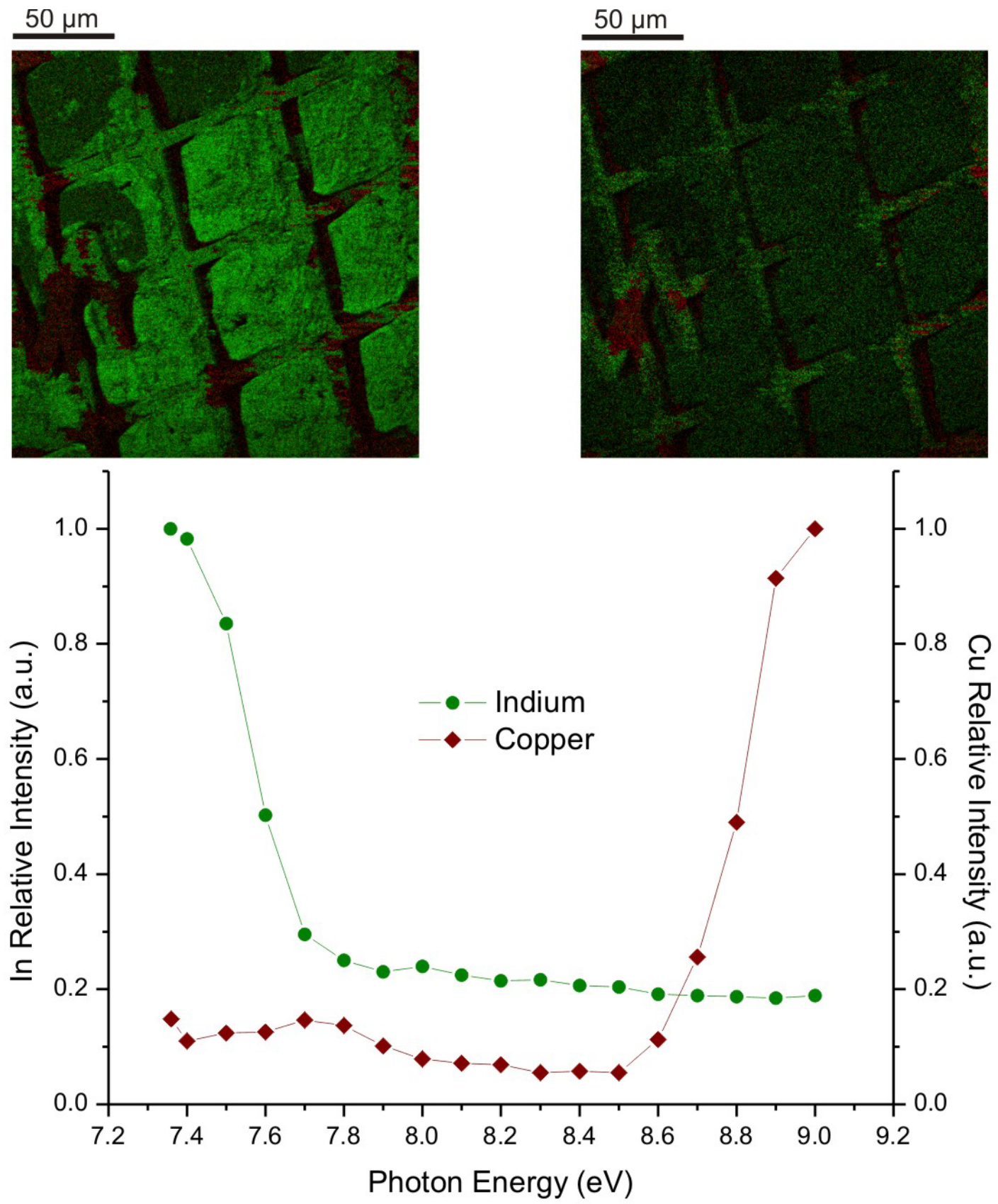

Figure 14 


\section{Future Light Source}

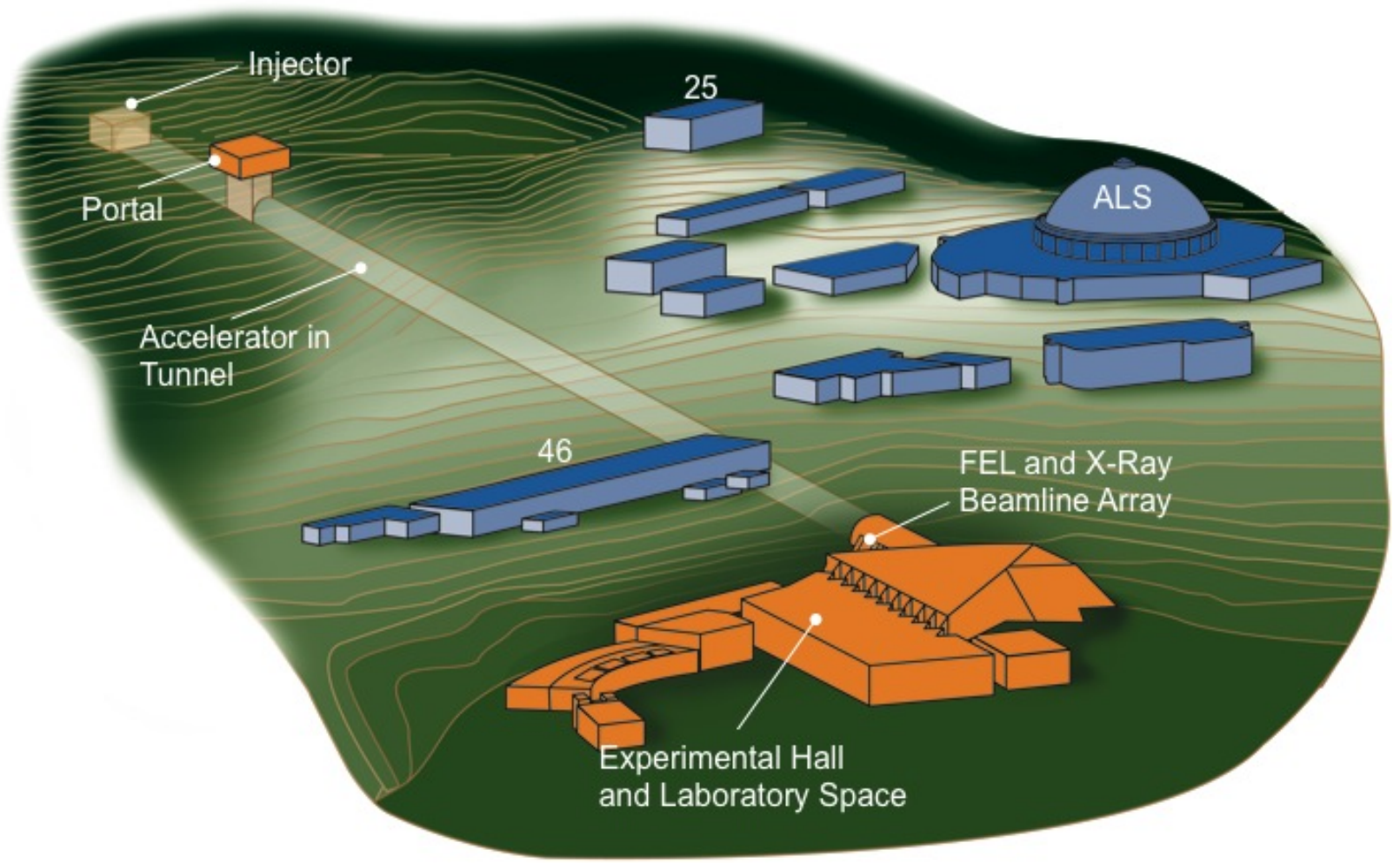

Figure 15 


\section{TOC graphic:}

Synchrotron radiation enables novel measurements of chemical dynamics for clusters, biological structure and imaging, isomeric species, aerosols, and planetary atmospheres.

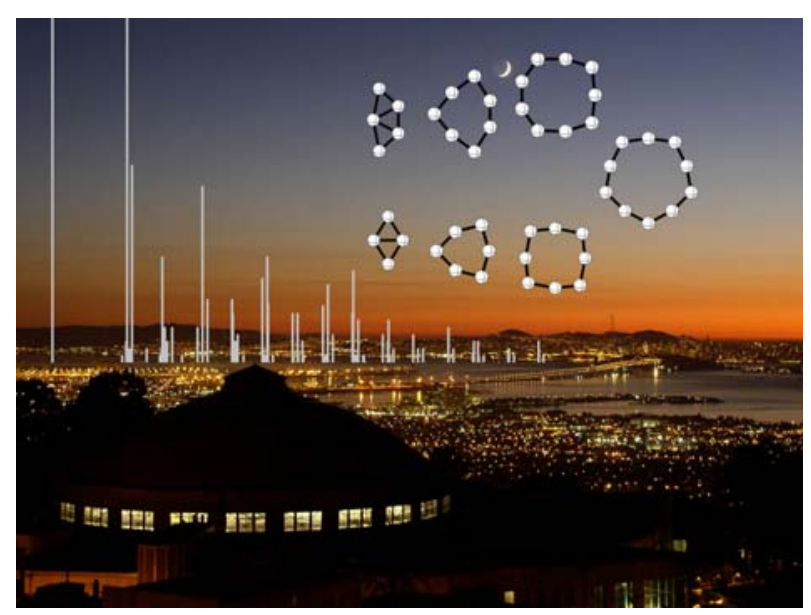

